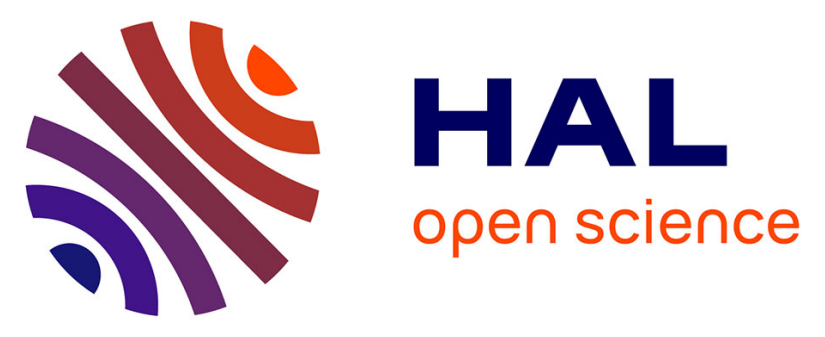

\title{
Titan's temporal evolution in stratospheric trace gases near the poles
}

\author{
Athena Coustenis, Donald E. Jennings, Richard K. Achterberg, Georgios \\ Bampasidis, Panayotis Lavvas, Conor A. Nixon, Nicholas A. Teanby, Carrie \\ M. Anderson, Valeria Cottini, F. Michael Flasar
}

\section{To cite this version:}

Athena Coustenis, Donald E. Jennings, Richard K. Achterberg, Georgios Bampasidis, Panayotis Lavvas, et al.. Titan's temporal evolution in stratospheric trace gases near the poles. Icarus, 2015, 270, pp.409-420. 10.1016/j.icarus.2015.08.027 . hal-01198804

\section{HAL Id: hal-01198804 https://hal.sorbonne-universite.fr/hal-01198804}

Submitted on 14 Sep 2015

HAL is a multi-disciplinary open access archive for the deposit and dissemination of scientific research documents, whether they are published or not. The documents may come from teaching and research institutions in France or abroad, or from public or private research centers.
L'archive ouverte pluridisciplinaire HAL, est destinée au dépôt et à la diffusion de documents scientifiques de niveau recherche, publiés ou non, émanant des établissements d'enseignement et de recherche français ou étrangers, des laboratoires publics ou privés. 


\section{Titan's temporal evolution in stratospheric trace gases near the poles}

Athena Coustenis ${ }^{1}$, Donald E. Jennings ${ }^{2}$, Richard K. Achterberg ${ }^{2,3}$, Georgios Bampasidis ${ }^{1,4}$, Panayiotis Lavvas ${ }^{5}$, Conor A. Nixon ${ }^{2}$, Nicholas A. Teanby ${ }^{6}$, Carrie M. Anderson ${ }^{2}$, Valeria Cottini $^{2,3}$, F. Michael Flasar ${ }^{2}$

${ }^{1}$ Laboratoire d'Etudes Spatiales et d'Instrumentation en Astrophysique (LESIA), Observatoire de Paris, PSL-Research Univ., CNRS, Univ. Pierre et Marie Curie Paris 06, Sorbonne Univ., Univ.

Paris-Diderot, Sorbonne Paris-Cité,

5, place Jules Janssen, 92195 Meudon Cedex, France; athena.coustenis@obspm.fr

${ }^{2}$ NASA Goddard Space Flight Center, Greenbelt, MD 20771, USA

${ }^{3}$ Department of Astronomy, University of Maryland, College Park, MD 20742, USA

${ }^{4}$ Faculty of Physics, National and Kapodistrian University of Athens, Panepistimioupolis, 15783

Zographos, Athens, Greece.

${ }^{5}$ GSMA, Université Reims Champagne-Ardenne, France.

${ }^{6}$ School of Earth Sciences, University of Bristol, Bristol BS8 1RJ, UK

Submitted to the Icarus Titan special issue: March 27, 2015

Revised version 2: 14 August, 2015

Corresponding author:

Athena Coustenis

Athena.coustenis@obspm.fr

LESIA (Bat. 18)

Observatoire de Meudon

92195 Meudon Cedex

France 


\begin{abstract}
We analyze spectra acquired by the Cassini/Composite Infrared Spectrometer (CIRS) at high resolution from October 2010 until September 2014 in nadir mode. Up until mid 2012, Titan's Northern atmosphere exhibited the enriched chemical content found since the Voyager days (November 1980), with a peak around the Northern Spring Equinox (NSE) in 2009. Since then, we have observed the appearance at Titan's south pole of several trace species for the first time, such as $\mathrm{HC}_{3} \mathrm{~N}$ and $\mathrm{C}_{6} \mathrm{H}_{6}$, observed only at high northern latitudes before equinox. We investigate here latitudes poleward of $50^{\circ} \mathrm{S}$ and $50^{\circ} \mathrm{N}$ from 2010 (after the Southern Autumnal Equinox) until 2014. For some of the most abundant and longest-lived hydrocarbons $\left(\mathrm{C}_{2} \mathrm{H}_{2}, \mathrm{C}_{2} \mathrm{H}_{6}\right.$ and $\left.\mathrm{C}_{3} \mathrm{H}_{8}\right)$ and $\mathrm{CO}_{2}$, the evolution in the past 4 years at a given latitude is not very significant within error bars especially until mid-2013. In more recent dates, these molecules show a trend for increase in the south. This trend is dramatically more pronounced for the other trace species, especially in 20132014 , and at $70^{\circ} \mathrm{S}$ relative to $50^{\circ} \mathrm{S}$. These two regions then demonstrate that they are subject to different dynamical processes in and out of the polar vortex region. For most species, we find higher abundances at $50^{\circ} \mathrm{N}$ compared to $50^{\circ} \mathrm{S}$, with the exception of $\mathrm{C}_{3} \mathrm{H}_{8}, \mathrm{CO}_{2}, \mathrm{C}_{6} \mathrm{H}_{6}$ and $\mathrm{HC}_{3} \mathrm{~N}$, which arrive at similar mixing ratios after mid-2013. While the $70^{\circ} \mathrm{N}$ data show generally no change with a trend rather to a small decrease for most species within 2014 , the $70^{\circ} \mathrm{S}$ results indicate a strong enhancement in trace stratospheric gases after 2012 . The $663 \mathrm{~cm}^{-1} \mathrm{HC}_{3} \mathrm{~N}$ and the $\mathrm{C}_{6} \mathrm{H}_{6} 674 \mathrm{~cm}^{-1}$ emission bands appeared in late 2011/early 2012 in the south polar regions and have since then exhibited a dramatic increase in their abundances. At $70^{\circ} \mathrm{S} \mathrm{HC}_{3} \mathrm{~N}, \mathrm{HCN}$ and $\mathrm{C}_{6} \mathrm{H}_{6}$ have increased by 3 orders of magnitude over the past 3-4 years while other molecules, including $\mathrm{C}_{2} \mathrm{H}_{4}, \mathrm{C}_{3} \mathrm{H}_{4}$ and $\mathrm{C}_{4} \mathrm{H}_{2}$, have increased less sharply by $1-2$ orders of magnitude). This is a strong indication of the rapid and sudden buildup of the gaseous inventory in the southern stratosphere during 2013-2014, as expected as the pole moves deeper into winter shadow. Subsidence gases that accumulate in the absence of ultraviolet sunlight, evidently increased quickly since 2012 and some of them may be responsible also for the reported haze decrease in the north and its appearance in the south at the same time.
\end{abstract}

Key words: Titan, atmosphere; Atmospheres, structure; Atmospheres, composition; Atmospheres, evolution; Satellites, composition 


\section{Introduction}

The haze and gaseous content in Titan's atmosphere has shown some significant and rapid evolution in the past few years. Titan has moved from northern winter through Northern Spring Equinox (NSE, in mid-2009) to northern summer. The reverse is true for the southern hemisphere. The gaseous and haze content of the atmosphere has exhibited features marking these seasonal passes. First, the Cassini Imaging Science Subsystem (ISS) and Visible and Infrared Mapping Spectrometer (VIMS) reported a high altitude cloud structure and a vortex at the south pole, developing between end of 2011 and mid-2012 (de Kok et al., 2014; West et al., 2015). The middle atmosphere, the stratosphere, showed evolution in temperature and chemical composition during the Cassini mission, especially in the north up to a couple of years ago (e.g. Achterberg et al., 2011; Teanby et al., 2010; Coustenis et al., 2010; Bampasidis et al., 2012; Coustenis et al., 2013). During the recent winter (2002-2009), the northern pole remained in darkness, allowing for photochemical hazes forming in the upper atmosphere to migrate downwards and accumulate in the stratosphere, where a maximum enhancement was observed during the NSE (e.g. Bampasidis et al., 2012). In association with circulation patterns where subsidence is expected in polar vortices, the seasonal effects significantly affect the temperature and the composition at the poles (Achterberg et al., 2008a; Teanby et al., 2012 and references therein). It has been shown that a reversal of the global dynamics on Titan is compatible with the observations as early as two years after NSE in the North (Bampasidis et al., 2012; Teanby et al., 2012; Vinatier et al., 2015). Jennings et al. (2012a,b) working with spectra acquire by the Cassini Composite Infrared Spectrometer (CIRS), reported that the intensity of a haze feature, with a signature at $220 \mathrm{~cm}^{-1}$, decreased in Titan's northern stratosphere by a factor of 4 over the period 2004-2012, while it appeared in the south after 2012. In more recent observations, Jennings et al. (2015) report further decrease in the north and increase in the South, with its emission centered southwards of $70^{\circ} \mathrm{S}$ and with a ring structure peaking at $10^{\circ}$ from the pole. As predicted by seasonal models, when the southern hemisphere experienced the advent of winter, the gaseous and haze composition changed and the vortex and the hood began appearing as the global circulation reversed, mimicking the situation found earlier in the north. From the high altitude haze hood (West et al., 2015) the trace gases are diffusing in the vortex to lower altitudes where they form more condensate layers. By end of 2012, just three years after Southern Autumnal equinox, the signs of these seasonal effects had already become quite prominent in Titan's thermal and chemical structure (e.g. Bampasidis et al., 2012; Teanby et al., 2012; Vinatier et al., 2015).

\section{Observations and analysis}

In this paper we extend previous work focusing on trace gases in Titan's stratosphere with emission signatures probing essentially the $100-400 \mathrm{~km}$ altitude range. We have been monitoring such emissions since the beginning of the Cassini mission in the focal plane 3 (FP3) of CIRS covering the spectral range from 600 to $1100 \mathrm{~cm}^{-1}$ (Coustenis et al., 2007, 2010, 2013; Bampasidis et al., 2012). Focal plane 4 (FP4) is used to extract the temperature profiles from the methane emission in the band centered at $1305 \mathrm{~cm}^{-1}$.

\section{Table 1}


Selections of spectra analyzed in this work (acquired in nadir mode at a spectral resolution of 0.5 $\mathrm{cm}^{-1}$ ). The characteristics of the averages are shown for the FP3 and the FP4 and for the Southern and Northern latitudes in chronological order. The spectra correspond to the 4.4 calibration version of the CIRS database. The averages are for $60-80^{\circ} \mathrm{S}, 60-80^{\circ} \mathrm{N}, 40-50^{\circ} \mathrm{S}$ and $40-50^{\circ} \mathrm{N}$.

\section{FP3 SPECTRA}

\begin{tabular}{lcccccc}
\hline Year & Month & $\begin{array}{c}\text { Cassini } \\
\text { Flyby }\end{array}$ & $\begin{array}{c}\text { Latitude } \\
\text { South }\end{array}$ & $\begin{array}{c}\text { Number of } \\
\text { spectra }\end{array}$ & Airmass & Ls $\left(^{\circ}\right)$ \\
\hline 2010 & Oct & (multiple) & $70^{\circ} \mathrm{S}$ & 498 & 1.7 & 15 \\
\hline 2011 & Sep & T78 & $70^{\circ} \mathrm{S}$ & 34 & 3.5 & 25 \\
\hline 2012 & Jun & $\mathrm{T} 84$ & $70^{\circ} \mathrm{S}$ & 584 & 1.2 & 36 \\
\hline 2012 & Sep & $\mathrm{T} 86$ & $50^{\circ} \mathrm{S}$ & 777 & 1.3 & 37 \\
\hline 2012 & Sep & $\mathrm{T} 86$ & $70^{\circ} \mathrm{S}$ & 590 & 1.6 & 37 \\
\hline 2013 & Apr & $\mathrm{T} 90$ & $45^{\circ} \mathrm{S}$ & 745 & 1 & 44 \\
\hline 2013 & May & $\mathrm{T} 91$ & $70^{\circ} \mathrm{S}$ & 78 & 1.3 & 45 \\
\hline 2014 & Jan & $\mathrm{T} 97$ & $70^{\circ} \mathrm{S}$ & 553 & 1.1 & 52 \\
\hline 2014 & Feb & $\mathrm{T} 98$ & $45^{\circ} \mathrm{S}$ & 532 & 1.1 & 53 \\
\hline & & & $\mathbf{N o r t h}^{\circ}$ & & & \\
\hline 2012 & Sep & $\mathrm{T} 86$ & $50^{\circ} \mathrm{N}$ & 761 & 1.2 & 37 \\
\hline 2013 & Sep & $\mathrm{T} 94$ & $50^{\circ} \mathrm{N}$ & 578 & 1.5 & 49 \\
\hline 2014 & Jan & $\mathrm{T} 97$ & $75^{\circ} \mathrm{N}$ & 1713 & 1 & 52 \\
\hline 2014 & Feb & $\mathrm{T} 98$ & $75^{\circ} \mathrm{N}$ & 1488 & 1 & 54 \\
\hline 2014 & Sep & $\mathrm{T} 105$ & $75^{\circ} \mathrm{N}$ & 541 & 1.8 & 60 \\
\hline
\end{tabular}

\section{FP4 SPECTRA}

\begin{tabular}{lcccccc}
\hline Year & Month & $\begin{array}{c}\text { Cassini } \\
\text { Flyby }\end{array}$ & $\begin{array}{c}\text { Latitude } \\
\text { South }\end{array}$ & $\begin{array}{c}\text { Number of } \\
\text { spectra }\end{array}$ & Airmass & Ls $\left(^{\circ}\right)$ \\
\hline 2010 & Oct & (multiple) & $70^{\circ} \mathrm{S}$ & 1050 & 2.9 & 15 \\
\hline 2011 & Sep & T78 & $70^{\circ} \mathrm{S}$ & 30 & 3.5 & 25 \\
\hline 2012 & Jun & T84 & $70^{\circ} \mathrm{S}$ & 356 & 1.2 & 36 \\
\hline 2012 & Sep & T86 & $50^{\circ} \mathrm{S}$ & 612 & 1.3 & 37 \\
\hline 2012 & Sep & T86 & $70^{\circ} \mathrm{S}$ & 1459 & 1.5 & 37 \\
\hline 2013 & Apr & T90 & $45^{\circ} \mathrm{S}$ & 745 & 1 & 44 \\
\hline 2013 & May & T91 & $70^{\circ} \mathrm{S}$ & 16 & 1.6 & 45 \\
\hline 2014 & Jan & T97 & $70^{\circ} \mathrm{S}$ & 1075 & 1.1 & 52 \\
\hline 2014 & Feb & T98 & $45^{\circ} \mathrm{S}$ & 532 & 1.1 & 53 \\
\hline & & & North & & & \\
\hline 2012 & Sep & T86 & $50^{\circ} \mathrm{N}$ & 831 & 1.3 & 37 \\
\hline 2013 & Sep & $\mathrm{T} 94$ & $50^{\circ} \mathrm{N}$ & 431 & 1.4 & 49 \\
\hline 2014 & Jan & $\mathrm{T} 97$ & $75^{\circ} \mathrm{N}$ & 854 & 1.1 & 52 \\
\hline 2014 & Feb & $\mathrm{T} 98$ & $75^{\circ} \mathrm{N}$ & 1397 & 1.2 & 54 \\
\hline 2014 & Sep & $\mathrm{T} 105$ & $75^{\circ} \mathrm{N}$ & 783 & 1.8 & 60 \\
\hline
\end{tabular}

We present here extensive surface-intercepting (nadir) stratospheric sounding of both Titan hemispheres in recent years (since Oct. 2010 and until Sept. 2014) for latitudes higher than $40^{\circ}$. 
We average nadir spectra available in these latitude ranges (around $50^{\circ} \mathrm{N}$ and $70^{\circ} \mathrm{N}$ and around $50^{\circ} \mathrm{S}$ and $70^{\circ} \mathrm{S}$ ) covering the FP3 and FP4 $600-1500 \mathrm{~cm}^{-1}$ range with a resolution of $0.5 \mathrm{~cm}^{-1}$ and taken during the Cassini mission flybys of the satellite (Table 1).

By including data up until September 2014, our data analysis here complements recent works cited hereabove and other investigations of the chemical and thermal composition of Titan (such as by Vinatier et al., 2015 which deals essentially with limb spectra taken at low and high CIRS spectral resolution at all latitudes including ones near the poles up to February 2012). Note that limb spectra inferences from studies such as by Teanby et al. (2012) and Vinatier et al. (2015) sound atmospheric levels at higher altitudes. The data selection criteria in Table 1 match those used by Bampasidis et al. (2012) and Coustenis et al. (2013) but are limited in this study by the CIRS coverage of the higher northern and southern latitudes. Fig. 1 shows that indeed highlatitude southern nadir CIRS spectra in high resolution and emission angles smaller than $60^{\circ}$ (so that they can be compatible with radiative transfer calculations) became available since late 2010 , whereas the same kind of data for high northern latitudes was only acquired since mid-2013. This explains the data selections analyzed in this paper as detailed in Table 1.

\section{$<$ insert Figure 1 $>$}

Fig. 1. Cassini/CIRS high-resolution coverage for latitudes $60-90^{\circ}$ in the Northern and Southern hemisphere of Titan from beginning of 2010 to end of 2014 and at emission angles smaller than $60^{\circ}$.

At high southern latitudes, in particular near and around $70^{\circ} \mathrm{S}$ (in fact from 60 to $80^{\circ} \mathrm{S}$ ), we have data from several flybys covering the 2010-2014 period. Fig. 2 shows the evolution in time of the emission observed in some of the CIRS spectral averages we have made in the 620 to 720 $\mathrm{cm}^{-1}$ range, where several molecules have signatures: $\mathrm{Q}$ branches of $\mathrm{C}_{4} \mathrm{H}_{2}, \mathrm{C}_{3} \mathrm{H}_{4}, \mathrm{HC}_{3} \mathrm{~N}, \mathrm{CO}_{2}$, $\mathrm{C}_{6} \mathrm{H}_{6}$, and $\mathrm{HCN}$ are visible, as well as R-wing lines of the $\mathrm{HCN}$ and $\mathrm{C}_{2} \mathrm{H}_{2}$ bands. Significant changes in the emission of several of the observed species are visible at high southern latitudes of Titan within a 2.5 year period. The changes in radiance are due to changes in temperature and abundance. Later in the paper we apply radiative transfer modeling to retrieve the pure abundance variations for these molecules, however it can already be seen that $\mathrm{HC}_{3} \mathrm{~N}$ appears to emerge in the spectra as early as September 2011 and to increase rapidly, bypassing the $\mathrm{CO}_{2}$ emission by June 2012, even when taking into account differences in band intensities, temperature and airmass effects. That means that $\mathrm{HC}_{3} \mathrm{~N}$ began actually increasing in the South before the $220 \mathrm{~cm}^{-1}$ haze (Jennings et al., 2012b). Benzene $\left(\mathrm{C}_{6} \mathrm{H}_{6}\right)$ also makes a first clear appearance in June 2012 and increases thereafter.

$<$ insert Figure $2>$

Fig. 2: Evolution in the past years of the emission observed in the $600-720 \mathrm{~cm}^{-1}$ spectral range in Titan's high Southern latitudes. From high left to bottom right the average latitude, number of spectra, and emission angle are included in the parentheses: 14 Oct $2010\left(71^{\circ} \mathrm{S}, 498,53^{\circ}\right), 11 \mathrm{Sep}$ $2011\left(71^{\circ} \mathrm{S}, 34,73^{\circ}\right), 27$ Jun $2012\left(71^{\circ} \mathrm{S}, 584,31^{\circ}\right), 30$ May $2013\left(73^{\circ} \mathrm{S}, 78,42^{\circ}\right)$. The emission angles are almost identical for the 2010 and 2013 observations. With the exception of the 2011 spectrum, which is noisy due to the small number of spectra co-added and the high emission angle, the other spectral averages have reasonable uncertainties and sufficient $\mathrm{S} / \mathrm{N}$ ratio so that the observed variations are real. However, temperature effects may also cause some bands to "appear" as decreasing. 
Indeed, one of the most spectacular changes during this period of time is observed for the $\mathrm{HC}_{3} \mathrm{~N}$ emission. In Fig. 3 (upper and middle panel) we show the $\mathrm{HC}_{3} \mathrm{~N}$ observations from both the northern and southern latitudes on a common seasonal timescale. Displaying results from north and south in this way is only valid if the two hemispheres behave similarly. Although north and south are probably not perfectly symmetric (based, for example, on orbital eccentricity and the distribution of lakes (e.g. Hayes et al., 2008)), we assume that they are similar enough in the stratospheric ranges to give us an accurate view of the seasonal cycle of the gases. The two upper panels of Fig. 3 indicate that $\mathrm{HC}_{3} \mathrm{~N}$ has dramatically decreased in the north $\left(\right.$ at $\left.50^{\circ} \mathrm{N}\right)$ since 2010 , while it has made a strong appearance in the south from 2012 onwards (compare results here with inferences from previous dates reported in Bampasidis et al., 2012). As shown also in Fig. 3 (lower panel), the $\mathrm{HC}_{3} \mathrm{~N}$ abundance decrease in the north essentially affects latitudes lower than $60^{\circ} \mathrm{N}$.

The method we apply here to the CIRS spectra is similar to the one described in previous papers (e.g. Coustenis et al., 2007, 2010; Bampasidis et al., 2012). The temperature is derived by the inversion of the emission recorded in the methane $v_{4}$ band at $1305 \mathrm{~cm}^{-1}$ following a procedure described in Achterberg et al., (2008a, 2011) and references therein. We adopt the $\mathrm{CH}_{4}$ vertical abundance profile measured by the Huygens GCMS instrument (Niemann et al., 2010) of 1.48\% above the cold trap, as in our previous analyses, which is quite compatible with the value derived by Bézard et al. (2014) from Huygens Descent Imager/Spectral Radiometer (DISR) measurements re-analysis. The haze component was inferred by adjusting the spectral dependence (Vinatier et al., 2012) for each latitudinal bin. We then use our line-by-line monochromatic radiative transfer code ARTT (for Atmospheric Radiative Transfer for Titan) to infer the mixing ratios or upper limits for 26 species in total detected or predicted in Titan's atmosphere (in addition to the main molecules such as $\mathrm{N}_{2}, \mathrm{H}_{2}, \mathrm{CH}_{4}$ and Ar, several hydrocarbons, nitriles and oxygen compounds, see Bampasidis et al., 2012 for details). The model includes the more recent (to our knowledge) spectroscopic parameters for the main species and their isotopologues (see full list in Coustenis et al., 2013). We apply this method to different latitudes from $40^{\circ} \mathrm{N}$ polewards and $40^{\circ} \mathrm{S}$ polewards by co-adding spectra in $60-80^{\circ} \mathrm{S}, 60-80^{\circ} \mathrm{N}, 40-50^{\circ} \mathrm{S}$ and $40-50^{\circ} \mathrm{N}$ bins. The mixing ratios are assumed to be vertically constant profiles above their condensation level except for the special treatment of the $\mathrm{C}_{2} \mathrm{H}_{2}$ strong emission band, which cannot be easily associated to a constant vertical profile, as well as for the uncertainties estimates, see Coustenis et al. (2010) and Bampasidis et al. (2012).

Since the model parameters for all the composition and temperature determinations are the same, we only consider the relative errors that are due to the data noise (taking into account the number of spectra and the noise equivalent spectral radiance (NESR) of the CIRS spectrometer), as well as to the calibration uncertainties, all of which error sources are usually small when a large number of spectra is averaged. The exceptions are $70^{\circ} \mathrm{S}$ September 2011 and May 2013 selections, where the error bars are in general larger due to the small number of averaged spectra, and other cases as pointed out hereafter. 


\section{$<$ insert Figure 3 : \\ a) upper panel \\ b) middle panel \\ c) lower panel >}

Fig. 3. Evolution of the $\mathrm{HC}_{3} \mathrm{~N}$ emission wrt other gases with spectral signatures nearby as a function of time and latitude: a) evolution of the $\mathrm{HC}_{3} \mathrm{~N}$ band in the South (Cassini flybys: 2006T19/T20, 2007-T38/T39, 2008-T41, 2009-T54/T55, 2010-T67, 2012-T86); b) evolution of the $\mathrm{HC}_{3} \mathrm{~N} 663 \mathrm{~cm}^{-1}$ emission band in the north with time (Cassini flybys: 2007-T24, 2008-T41-45, 2009-T51, 2010-T65/T66, 2012-T86). The small variations observed for stronger molecules like $\mathrm{CO}_{2}$ and $\mathrm{HCN}$ are due to differences in temperature and/or the secant, but clearly $\mathrm{HC}_{3} \mathrm{~N}$ decreases in the north and appears in the South; c) In the north, in $2010, \mathrm{HC}_{3} \mathrm{~N}$ is restrained only to higher latitudes $\left(>50^{\circ} \mathrm{N}\right)$ as seen in spectral selections from T65-T66 flybys, and it does not appear at $40^{\circ} \mathrm{N}$.

\section{Results}

We performed radiative transfer simulations of the Titan spectra at different latitudes and seasons and compared results at different latitudes. In our simulations we use the temperature profiles derived by fitting the methane $v_{4}$ band in FP4. The thermal structure is derived using an a priori approach described in Achterberg et al. (2008a, 2011). We fit the continuum with a simple 2-layer cloud model for the FP3 and FP4 spectral regions. We then infer the haze dependence and from the emission in the molecular bands we derive the abundances that we discuss hereafter. Details of our method are given in Coustenis et al. (2007, 2010) and Bampasidis et al. (2012).
$<$ insert Figure 4 :
a) upper panel, left
b) upper panel, right
c) middle panel, left
d) middle panel, right
e) lower panel, left
f) lower panel, right $>$

Fig. 4. Contribution functions of methane at $1305 \mathrm{~cm}^{-1}$ (upper two panels for $\mathrm{Q}$ and $\mathrm{R}$ branches) from its FP4 emission and of other species with signatures in FP3 (middle and lower panels) and the evolution with time at $75^{\circ} \mathrm{S}$. The emission in the methane band originates significantly from 0.3 mbar in the Q branch (a) but also from atmospheric pressure levels higher and lower in the stratosphere in the band wings (up to $10^{-3} \mathrm{mbar}$ and as low as $10 \mathrm{mbar}$ ), especially in recent times. Depending on the epoch, the emission of several trace gases comes not only from around 10 mbar but also from higher atmospheric levels around 0.5 mbar.

Fig. 4 shows the contribution functions (CFs) calculated for the methane $v_{4}$ band and for several other molecules at $70^{\circ} \mathrm{S}$. These plots indicate the regions sounded in the CIRS spectra for 
the thermal profile $(4 \mathrm{a}, \mathrm{b})$ via the methane emission in FP4 and for the molecular abundances (4cf) from their emission bands in FP3. The shape of the CFs and their evolution with time for $\mathrm{C}_{2} \mathrm{H}_{4}$ is similar to that of $\mathrm{C}_{2} \mathrm{H}_{6}$, for $\mathrm{CO}_{2}, \mathrm{C}_{3} \mathrm{H}_{4}$ and $\mathrm{C}_{3} \mathrm{H}_{8}$ similar to that of $\mathrm{C}_{4} \mathrm{H}_{2}$ and for $\mathrm{C}_{6} \mathrm{H}_{6}$ similar to that of $\mathrm{HCN}$. For the $\mathrm{CFs}$ of the different species and the regions probed at mid-latitudes see Bampasidis et al. (2012) and Coustenis et al. (2013).

\subsection{Temperature profiles}

The temperature profiles shown in Fig. 5 are for high Northern and Southern latitudes (beyond $50^{\circ} \mathrm{N}$ and $50^{\circ} \mathrm{S}$ ) at different dates. The uncertainty on these inferences is very small for the mid latitudes (about $0.1 \mathrm{~K}$ ) at all pressure levels up to $0.01 \mathrm{mbar}$. When the uncertainty on the initial guess profile and the methane mole fraction is taken into account, the $3-\sigma$ error bar is about $1.5 \mathrm{~K}$ at $1 \mathrm{mbar}$ and $2.5 \mathrm{~K}$ at 0.05 and $5 \mathrm{mbar}$ for the mid-latitude profiles. For the higher northern and southern latitudes the situation is different as the uncertainty on the retrievals per se is larger. For the $70^{\circ} \mathrm{N}$ profiles, the $3-\sigma$ error bar is about $2 \mathrm{~K}$ at the $1 \mathrm{mbar}$ level and $3-4 \mathrm{~K}$ at 0.05 and $5 \mathrm{mbar}$ (Fig. 5). For the $70^{\circ} \mathrm{S}$ thermal profiles, the error bars are similar to $70^{\circ} \mathrm{N}$ up to 2013 but considerably higher as the temperatures become very cold after 2014 when the calibration is more uncertain and the number of spectra averaged generally smaller : 5-7 K at lower altitudes and up to $10 \mathrm{~K}$ at $0.05 \mathrm{mbar}(300 \mathrm{~km}$ in altitude).

We find that as the Southern hemisphere moved into winter after 2010, strong temperature variations are observed essentially in that pole. For $50^{\circ} \mathrm{N}$, Fig. 5 (left panel) shows little to no variation during the past years in the lower stratosphere (up to $0.5 \mathrm{mbar}$ ), while the upper stratosphere has warmed up by $10 \mathrm{~K}$ or more. At $50^{\circ}$ in latitude we have been at the border of the northern vortex, which is weakening in the past years so that the temperature is increasing now in the absence of active radiative emitters and with increasing sunlight.

The latitudes around $50^{\circ} \mathrm{S}$ show a $15 \mathrm{~K}$ decrease from 2010 to 2012 and then slightly warm up again by about $8-10 \mathrm{~K}$ until early 2014 , but are still colder than in 2010 . We also note that in 2013 and 2014 the $50^{\circ} \mathrm{S}$ thermal profiles are very similar throughout the stratosphere and no further indication of changes in temperature are observed. Our observations of the equatorial latitudes at the same time, indicate that - as for the $50^{\circ} \mathrm{N}$ - no significant changes exist in the lower stratosphere, while a $5 \mathrm{~K}$ cooling is found at pressures lower than $0.5 \mathrm{mbar}$ since May 2011, stabilizing after that.

The right panel in Fig. 5 clearly shows a dramatic decrease in temperature in the stratosphere (from 0.1 down to 1 mbar pressure levels) for the higher Southern latitudes, at $70^{\circ} \mathrm{S}$, since 2010, whereas a smaller warming is observed in the summer-entering North only since early 2014. Thus, the warming in the North from February until September 2014 is about 6 K, whereas at about the same period of time, the South has become another 12-15 K colder in the stratosphere, totaling about a $40 \mathrm{~K}$ drop in temperature within 4 years since 2010 . Before that time, there were no significant temporal variations in temperature reported since the beginning of the Cassini mission in that region around $50^{\circ} \mathrm{S}$, whereas again prior to 2010 the mid-northern latitudes had generally shown a tendency for decreasing temperatures in the stratosphere (see Bampasidis et al., 2012). The CFs for the center and the left wing of the $v_{4} \mathrm{CH}_{4}$ band (Figs 4a,b) at $70^{\circ} \mathrm{S}$ show that the emission of methane originates significantly from 0.1 to 10 mbar in the $Q$ branch, peaking essentially around 0.3-0.5 mbar. The wings of the band probe even higher (and also lower) atmospheric pressure levels (up to $10^{-3} \mathrm{mbar}$ and as low as from around $10 \mathrm{mbar}$ ), especially in recent times. Thus, in January 2014 the CF peaks near 0.05 mbar and near 0.005 mbar in September 2014. This has to do with the colder temperatures and the thermal profile's 
shape departing from rather constant values above $200 \mathrm{~km}$ until 2012 and exhibiting an increasing slope towards warmer temperatures thereabove since then.

Pre-equinox variations at $70^{\circ} \mathrm{N}$ and $70^{\circ} \mathrm{S}$ are discussed in Achterberg et al. (2011) and Teanby et al. (2012). The northern pre-equinox temperatures in general showed a complicated behavior. The upper stratosphere/lower mesosphere were cooling. The middle stratosphere $(\sim 200 \mathrm{~km}$ and lower) was warming at mid-latitudes; at polar latitudes the mid-stratosphere initially warmed and then started cooling again (see Achterberg et al., 2011 for details). The drop in temperature for the higher Southern latitudes found here and reported previously is matched with an enhancement in gas and haze content as will be shown hereafter.

\section{$<$ insert Figure 3 :}

a) left

b) right $>$

Fig. 5. (left panel) : temperature variations at $50^{\circ} \mathrm{S}$ (solid lines) and $50^{\circ} \mathrm{N}$ (dashed lines) in Titan's stratosphere from January 2010 until February 2014; (right panel) : temperature profiles of Titan at $70^{\circ} \mathrm{S}$ (solid lines) and $70^{\circ} \mathrm{N}$ (dashed lines) with dates ranging from October 2010 to September 2014. The pressure/altitude ranges probed by these profiles vary with latitude, but are generally in the $0.1-20$ mbar region. The 3- $\sigma$ error bars on the temperature are plotted at $0.05,1$ and 5 mbar (see text for details). As can be seen, the stratospheric temperatures in the 0.1 to 1 mbar pressure range dropped by about $40 \mathrm{~K}$ near the Southern pole within the past 4 years. At the same time, the temperatures in the North had not indicated similar dramatic changes, but rather an increase in temperature is found since February 2014, as the North moves into summer. The dashed lines thus show that within about 7 months since December 2013, the North pole had warmed up by about $6 \mathrm{~K}$ (see text).

The temperature profiles at $70^{\circ} \mathrm{S}$ for the period in time from 2010 to 2012 are compatible within uncertainties with those found by Vinatier et al. (2015) from limb-viewing observations in the stratospheric region that we probe here and show again a decrease in temperature by about 10 K. Similarly, their mid-latitude southern and northern profiles, as well as the thermal profiles close to $70^{\circ} \mathrm{N}$ do not exhibit large variations, as also found here and with compatible trends (see Section 3.2 for more details).

\subsection{The chemical composition}

With the temperature defined in the stratosphere and the continuum fitted by adapting the haze, we produce spectra simulating Titan's chemical composition though the various emission bands. Examples of fits of the Titan observations obtained with our radiative transfer code ARTT are shown in Fig. 6. The full method is described in Coustenis et al., (2013, Section 3 and references therein). In order to derive the abundances, we fit the $\mathrm{Q}$ branches of the different molecules (and the wings separately for $\mathrm{C}_{2} \mathrm{H}_{2}$, see Coustenis et al., 2013) by minimizing the residuals in the fits we obtain through an iterative process.

The contribution functions of $\mathrm{C}_{2} \mathrm{H}_{2}$ (Fig. 4c) indicate that its emission in the $728 \mathrm{~cm}^{-1}$ band at $70^{\circ} \mathrm{S}$ originated from around 2 mbar in $2010(\sim 155 \mathrm{~km})$ but is currently sounding lower atmospheric levels at around 10 mbar $\left(100 \mathrm{~km}\right.$ in altitude). The $\mathrm{C}_{2} \mathrm{H}_{6}$ (Fig. $\left.4 \mathrm{~d}\right)$ as well as $\mathrm{C}_{2} \mathrm{H}_{4}$, 
$\mathrm{C}_{3} \mathrm{H}_{8}$ and $\mathrm{CO}_{2}$ emission bands, probed pressures from 0.5 to $10 \mathrm{mbar}$ in earlier dates $(100-200 \mathrm{~km}$ in altitude), while since 2014 their emission is narrowed down to levels around $10 \mathrm{mbar}$ (around $100 \mathrm{~km}$ ), but still with some emission coming from around 0.3-0.5 mbar or higher. $\mathrm{C}_{4} \mathrm{H}_{2}$ and $\mathrm{C}_{3} \mathrm{H}_{4}$ emission bands probe pressures around 10 mbar $(100 \mathrm{~km})$ throughout time. HCN (as well as $\left.\mathrm{C}_{6} \mathrm{H}_{6}\right)$ started out sounding levels around 7 mbar $(110 \mathrm{~km})$ but are now showing emission coming also from higher levels around $0.4 \mathrm{mbar}(200 \mathrm{~km})$ in January 2014 and $0.1 \mathrm{mbar}(250 \mathrm{~km})$ in Sept. 2014 (Fig. 4f). Finally, $\mathrm{HC}_{3} \mathrm{~N}$ (also shown in Fig. 4f) probed the stratosphere at around 10 mbar $(100 \mathrm{~km})$ initially and only in September 2014 its CF has shown an additional component from around 0.5 mbar $(190 \mathrm{~km})$.

In brief, with the exception of $\mathrm{HCN}, \mathrm{HC}_{3} \mathrm{~N}$ and $\mathrm{C}_{6} \mathrm{H}_{6}$, we find the emission observed in most trace gases to be originating in recent times from stratospheric levels around $10 \mathrm{mbar}(100 \mathrm{~km})$ having previously probed higher levels (from around $200 \mathrm{~km}$ ) in some cases. The contrary is found for the two nitriles and benzene, where the levels sounded have raised from $10 \mathrm{mbar}$ (100 $\mathrm{km})$ up to around $0.5 \mathrm{mbar}$ or higher $(250-300 \mathrm{~km})$.

Our results for $\mathrm{C}_{2} \mathrm{H}_{2}, \mathrm{C}_{2} \mathrm{H}_{6}, \mathrm{C}_{3} \mathrm{H}_{8}$ and $\mathrm{CO}_{2}$ at mid latitudes $\left(50^{\circ} \mathrm{N}\right.$ and $\left.50^{\circ} \mathrm{S}\right)$ follow up on our previous estimations of these abundances in Bampasidis et al. (2012) and Coustenis et al. (2013), to which we add here a few points from the couple past years.

\section{$<$ insert Figure 6 : \\ a) upper panel \\ b) middle panel \\ c) lower panel, left \\ d) lower panel, right $>$}

Fig. 6. (upper panel) extract from CIRS FP4 in the $1250-1350 \mathrm{~cm}^{-1}$ range where we observe the emission of the methane $v_{4}$ band in September 2014 at $75^{\circ} \mathrm{S}$; (middle panel) extract of CIRS FP3 in the $620-850 \mathrm{~cm}^{-1}$ range where several emission bands are observed $\left(\mathrm{HCN}, \mathrm{C}_{2} \mathrm{H}_{2}, \mathrm{C}_{3} \mathrm{H}_{8}, \mathrm{C}_{2} \mathrm{H}_{6}\right)$ in April 2013 at $45^{\circ} \mathrm{S}$; (lower panel) zoom in the $620-680 \mathrm{~cm}^{-1}$ range for September 2014 at $75^{\circ} \mathrm{N}$ (left) and September 2012 at $75^{\circ} \mathrm{S}$ (right) showing the $\mathrm{C}_{4} \mathrm{H}_{2}, \mathrm{C}_{3} \mathrm{H}_{4}, \mathrm{HC}_{3} \mathrm{~N}, \mathrm{CO}_{2}$, and $\mathrm{C}_{6} \mathrm{H}_{6}$ emission bands (the vertical scale is different for the two lower zooms).

Our calculations indicate that the mixing ratios of some of the most abundant molecules in Titan's stratosphere (Fig. 7) at $50^{\circ} \mathrm{N}$ do not vary very much with time from 2010 to 2014 . They remain also larger than the $50^{\circ} \mathrm{S}$ ones up to 2013 , after which there is a trend for the latter to increase for $\mathrm{C}_{2} \mathrm{H}_{6}, \mathrm{C}_{3} \mathrm{H}_{8}$ and $\mathrm{CO}_{2}$. Prior to that, during the 2010 to 2013 time frame, the $50^{\circ} \mathrm{N}$ abundances for $\mathrm{C}_{2} \mathrm{H}_{2}$ and $\mathrm{C}_{3} \mathrm{H}_{8}$ were higher than the $50^{\circ} \mathrm{S}$ by factors of about 2-3 (comparing blue and green curves on Fig. 7). Note that in 2012 we did not have CIRS high-resolution spectra for latitudes close to $50^{\circ} \mathrm{S}$. The green values plotted in this figure and in Fig. 10 for September 2012 then correspond to abundances close to $60^{\circ} \mathrm{S}$. This explains why for some of the molecules more affected by the seasonal changes the plotted abundances are higher than expected.

For $\mathrm{C}_{2} \mathrm{H}_{6}$ and $\mathrm{CO}_{2}$, the difference in abundance between $50^{\circ} \mathrm{N}$ and $50^{\circ} \mathrm{S}$ was $30-50 \%$ to the benefit of the North. In more recent times, however, the abundances of all these molecules have reached similar values at $50^{\circ} \mathrm{N}$ and $50^{\circ} \mathrm{S}$. There seems therefore to be a trend for a flat or a decreasing abundance in the northern latitudes around $50^{\circ} \mathrm{N}$ and an increase in the southern abundances around $50^{\circ} \mathrm{S}$ for all these molecules (in particular for $\mathrm{C}_{3} \mathrm{H}_{8}$ and $\mathrm{CO}_{2}$ ). However, we have barely $3-4$ points at $50^{\circ} \mathrm{N}$ and $50^{\circ} \mathrm{S}$ during that period of time and the uncertainties do not 
allow us to make firm statements. Nevertheless, when we take into account the inferences also from the early dates of the Cassini mission in 2006 (Bampasidis et al. 2012; Coustenis et al., 2013), the trends appear strengthened.

\section{$<$ insert Figure 7 : \\ a) upper panel, left \\ b) upper panel, right \\ c) lower panel, left \\ d) lower panel, right $>$}

Fig. 7. Retrieved abundances in the stratosphere of Titan for some of the most abundant molecules in Titan's atmosphere, $\mathrm{C}_{2} \mathrm{H}_{6}, \mathrm{C}_{2} \mathrm{H}_{2}$ and $\mathrm{C}_{3} \mathrm{H}_{8}$ and $\mathrm{CO}_{2}$, from 2010 to 2014 at different high northern and southern latitudes : $50^{\circ} \mathrm{N}$ (blue), $70^{\circ} \mathrm{N}$ (black), $50^{\circ} \mathrm{S}$ (green) and $70^{\circ} \mathrm{S}$ (red). The vertical lines correspond to $3-\sigma$ uncertainties. The error bars on the 2011 and May $201370^{\circ} \mathrm{S}$ inferences are larger than at other times due to the poor quality of the spectral selection as explained in Section 2. Also note that the 2012 September green values are not for $50^{\circ} \mathrm{S}$ but for $60^{\circ} \mathrm{S}$, hence larger than adjacent values in some cases.

Moving closer to the poles, at $70^{\circ} \mathrm{S}$ (red curves in Fig. 7), within the past 4 years or so, since late 2010, $\mathrm{CO}_{2}$ does not show any significant variations within error bars, but we note that its high northern and southern latitude values are quite similar since mid-2013 after respective decrease and increase of the abundances. The other molecules $\left(\mathrm{C}_{2} \mathrm{H}_{2}, \mathrm{C}_{2} \mathrm{H}_{6}\right.$ and $\left.\mathrm{C}_{3} \mathrm{H}_{8}\right)$ were quite constant in time up to early 2014 near the poles, but since then, in the past year or so, these species show an increase in abundance at $70^{\circ} \mathrm{S}$ (by factors of $2-3$ with respect to the 2010 values). Comparing furthermore the $70^{\circ} \mathrm{N}$ and $70^{\circ} \mathrm{S}$ results within the year 2014 (when we have data for both latitudes), we find a significant positive evolution near the South pole, whereas the Northern polar regions remain rather stable or perhaps even showing a trend towards a decrease (Fig. 7). Thus, from early 2014 until September 2014 , we find the $70^{\circ} \mathrm{S}$ values of all of these constituents to have become similar or even higher than the $70^{\circ} \mathrm{N}$.

Figure 8 shows the profiles of trace gas emission through the pole displaying the radiance at given wavelengths and its variation through the trace. The longitudinal average here is small enough that the two different sides are kept separate. Comparing the plots of the profiles at Titan's southern pole at two different dates within 2014 spanning 9 months on Fig. 8, we find that $\mathrm{C}_{2} \mathrm{H}_{2}, \mathrm{C}_{2} \mathrm{H}_{6}, \mathrm{HCN}$ and $\mathrm{CO}_{2}$ are low in emission or about the same at the pole with respect to lower latitudes. For other species, the curves in January show a gas emission collar, as reported in 2012 for the haze $220 \mathrm{~cm}^{-1}$ feature (Jennings et al., 2012b; 2015) within $30^{\circ}$ from the South pole and centered at $10^{\circ}$. This gas emission collar is shifted about 4 degrees from the pole, in agreement with the tilt found in Titan's atmosphere (Achterberg et al., 2008b; Jennings et al., 2015) and was still evolving rapidly during 2014 while changes can be seen from one Titan flyby to the next (as schematically represented in Fig. 8) in particular for latitudes within $30^{\circ}$ from the South pole. In particular, tracing cyanoacetylene $\left(\mathrm{HC}_{3} \mathrm{~N}\right)$ with medium spectral resolution maps, we find its abundance to be increasing steadily since 2012 (Fig. 9). $\mathrm{HC}_{3} \mathrm{~N}$ developed the ring shape since 2012, and has been evolving rapidly since early 2014.

However, by September most of the molecules do not show any more this ring shape, and the increased abundance further away from the immediate vicinity of the pole (the so-called "sombrero shape") is no longer present. Indeed, the secondary, less abundant, gases (like $\mathrm{C}_{4} \mathrm{H}_{2}$ and $\mathrm{C}_{3} \mathrm{H}_{4}$ ) have now taken on the "hood" shape that is familiar in the north (Fig. 8). Benzene (and 
perhaps $\mathrm{HC}_{3} \mathrm{~N}$ ) tend to exhibit a somewhat different behavior by retaining higher concentrations near the pole all the way to September 2014. This could be indicative of the fact that the material arriving at the pole and then spreading out, is not necessarily settling in a uniform pattern.

\section{$<$ insert Figure $8>$}

Fig. 8. Trace gas emission in Titan's southern hemisphere at two different dates within 2014 : in January and September 2014 (from 97 RTI data). The relative intensities and not the absolute radiances are displayed on the figure, in order to show the trends with latitude. The profiles were scaled for each gas to facilitate comparison. Comparing the plots in September with those in January the previously observed so-called "sombrero shape" is found to no longer be present. The secondary, less abundant, gases $\left(\mathrm{HC}_{3} \mathrm{~N}, \mathrm{C}_{4} \mathrm{H}_{2}, \mathrm{C}_{3} \mathrm{H}_{4}\right.$ and $\left.\mathrm{C}_{6} \mathrm{H}_{6}\right)$ have now taken on the "hood" shape that is familiar in the north. $\mathrm{C}_{6} \mathrm{H}_{6}\left(\right.$ and $\left.\mathrm{HC}_{3} \mathrm{~N}\right)$ seem to be exhibiting a somewhat different behavior from the other gases because they appear to be still concentrated near the pole in September 2014, although the other secondary gases had become more broadly distributed (see text).

\section{$<$ insert Figure 9 >}

Fig. 9. Polar orthographic projection maps of $\mathrm{HC}_{3} \mathrm{~N}$ emission at $663 \mathrm{~cm}^{-1}$ over Titan's southern hemisphere from $30^{\circ} \mathrm{S}$ to $90^{\circ} \mathrm{S}$ from $2.5 \mathrm{~cm}^{-1}$ resolution spectra. The asymmetry seen on the plot is most probably due to differences in the emission angles.

From 2010 and until 2014, several of the molecules in Fig. 10 show differences between $50^{\circ} \mathrm{S}$ and $50^{\circ} \mathrm{N}$ with abundances larger for the north by factors of 3-6 for $\mathrm{C}_{2} \mathrm{H}_{4}, \mathrm{C}_{3} \mathrm{H}_{4}$ and $\mathrm{C}_{4} \mathrm{H}_{2}$, and by more than an order of magnitude for $\mathrm{HCN}$. The values we retrieve for $\mathrm{HC}_{3} \mathrm{~N}$ and $\mathrm{C}_{6} \mathrm{H}_{6}$, after starting with larger abundances in the north, become quite similar at these latitudes, in particular after 2012. Our calculations thus indicate for instance that already in September 2012, the $\mathrm{HC}_{3} \mathrm{~N}$ abundance was almost an order of magnitude higher in the south $\left(3 \times 10^{-9}\right)$ than in the north (at some $5 \times 10^{-10}$ ), whereas the opposite was true in 2010 (about $1 \times 10^{-9}$ in the north vs $1 \times 10^{-10}$ in the South). Similarly for $\mathrm{C}_{6} \mathrm{H}_{6}$, starting with an upper limit in 2010 at $50^{\circ} \mathrm{S}$ which was 50 times lower than its $50^{\circ} \mathrm{N}$ counterpart, its abundance increases rapidly becoming similar in 2012 and even higher than the $50^{\circ} \mathrm{N}$ or the $70^{\circ} \mathrm{N}$ in later dates.

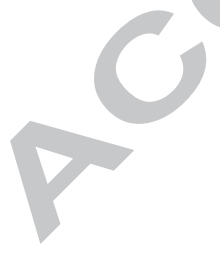

$<$ insert Figure 10 :

a) upper panel, left

b) upper panel, right

c) middle panel, left

d) middle panel, right

e) lower panel, left

f) lower panel, right $>$

Fig. 10. As for Fig. 7 but for $\mathrm{C}_{2} \mathrm{H}_{4}, \mathrm{C}_{3} \mathrm{H}_{4}, \mathrm{C}_{4} \mathrm{H}_{2}, \mathrm{C}_{6} \mathrm{H}_{6}, \mathrm{HCN}$ and $\mathrm{HC}_{3} \mathrm{~N}$. For benzene, the starting values in 2010 at high southern latitudes are 3- $\sigma$ upper limits. Note that, as in Fig. 7, the 2012 
September green values correspond to $60^{\circ} \mathrm{S}$ rather than $50^{\circ} \mathrm{S}$, hence the higher than expected values for some molecules (see text). Arrows indicate upper limits.

Within error bars, as for the more abundant molecules, the trace gases shown in Fig. 10 do not exhibit any significant variations at $50^{\circ} \mathrm{N}$, although after 2012 we could only derive upper limits for $\mathrm{C}_{6} \mathrm{H}_{6}$ and $\mathrm{HC}_{3} \mathrm{~N}$. Similarly, for $50^{\circ} \mathrm{S}$ there is no clear indication for either an increase or decrease in the observed abundances given the uncertainties, with perhaps the exception of $\mathrm{HC}_{3} \mathrm{~N}$ and $\mathrm{C}_{6} \mathrm{H}_{6}$ which seem to increase significantly from 2010 to 2014 . We note, however, that the data are scarce between 2010 and late 2012 at $50^{\circ} \mathrm{S}$ and $50^{\circ} \mathrm{N}$ (only two date points exist : April 2010 and September 2012 for $50^{\circ} \mathrm{S}$ and January 2010 and September 2012 for $50^{\circ} \mathrm{N}$ ) and furthermore, for $\mathrm{C}_{6} \mathrm{H}_{6}$ the $201050^{\circ} \mathrm{S}$ and $70^{\circ} \mathrm{S}$ results are in fact upper limits. We also remind the reader that for September 2012, the green values - otherwise representing latitudes close to $50^{\circ} \mathrm{S}-$ are actually inferences for $60^{\circ} \mathrm{S}$ in average. Therefore, the $\mathrm{HC}_{3} \mathrm{~N}, \mathrm{C}_{4} \mathrm{H}_{2}$ and $\mathrm{C}_{3} \mathrm{H}_{4}$ abundances are higher than expected and an artificial bend is created because we are at $60^{\circ} \mathrm{S}$ and not at $50^{\circ} \mathrm{S}$ latitude. This is the result of the different response to the seasonal effects as a function of latitude as discussed in Section 2 and shown in Fig. 3c.

We do not have any data at $70^{\circ} \mathrm{N}$ before 2014 , so we do not know how the abundances of these species evolved prior to the past year. With that caveat in mind, our RT results at high Northern and Southern latitudes (at about $20^{\circ}$ from the poles), show that the North pole is now as abundant in $\mathrm{C}_{3} \mathrm{H}_{4}$ and $\mathrm{C}_{4} \mathrm{H}_{2}$ as the South pole (Fig. 10). We note that for these two molecules the $70^{\circ} \mathrm{S}$ content has increased considerably from late 2010 until September 2014, by a factor of 4 for $\mathrm{C}_{3} \mathrm{H}_{4}$ and more than an order of magnitude for $\mathrm{C}_{4} \mathrm{H}_{2}$. For the other trace molecules shown in Fig. 10, the higher southern latitudes have become largely more enhanced than the North by late 2014 . For $\mathrm{C}_{2} \mathrm{H}_{4}$ and $\mathrm{HCN}$ the mixing ratios have increased at $70^{\circ} \mathrm{S}$ by $1-3$ orders of magnitude since September 2011, making $\mathrm{C}_{2} \mathrm{H}_{4}$ almost 4 times more abundant near the South pole of Titan in September 2014, while HCN at the same time is about 2 orders of magnitude more abundant at $70^{\circ} \mathrm{S}$ than at $70^{\circ} \mathrm{N}$. For $\mathrm{C}_{6} \mathrm{H}_{6}$ and $\mathrm{HC}_{3} \mathrm{~N}$ the increase is even more dramatic at $70^{\circ} \mathrm{S}$ representing 3 orders of magnitude or more since late 2010 for $\mathrm{HC}_{3} \mathrm{~N}$ and since late 2011 for $\mathrm{C}_{6} \mathrm{H}_{6}$ (note that we only have upper limits prior to that date for these molecules) and these species are now significantly more enhanced at $70^{\circ} \mathrm{S}$ than at $70^{\circ} \mathrm{N}$ (by more than one and three orders of magnitude respectively).

Nitriles, and in particular $\mathrm{HC}_{3} \mathrm{~N}$ which may serve as a tracer for complex nitriles, have been proposed as precursors for the haze and clouds observed in Titan's atmosphere (Lavvas et al., 2011, Anderson \& Samuelson 2011, Jennings et al., 2012a, Vinatier et al., 2012 and references therein) because of similar variations suggesting a common origin. As Figs. 2 and 3 already show here, the $663 \mathrm{~cm}^{-1} \mathrm{HC}_{3} \mathrm{~N}$ band intensity at the south pole has been essentially nil since 2006 until as recently as late 2011 . Then in late 2011 and early 2012 the intensity of $\mathrm{HC}_{3} \mathrm{~N}$ suddenly became visible at latitudes higher than $50^{\circ} \mathrm{S}$ (Figs. 8,9), which is what is also reported by Jennings et al., (2012a,b and references therein). The advent of the $\mathrm{HC}_{3} \mathrm{~N}$ in the south came three years after equinox. By that time the haze intensity in the north had greatly decreased since the beginning of the mission and was comparable to the haze appearing in the south (Jennings et al., 2012a). As these authors reported, the increase of the emission in the south is much faster than the decrease in the north; this is similar to what we find here. We do not have data at $70^{\circ} \mathrm{N}$ to compare with $70^{\circ} \mathrm{S}$ at dates earlier than 2014 , so we cannot discern if the increase in the North corresponds to a decrease in the South, nor can we infer a transition time at such high latitudes.

Our results for the molecules shown in Figs. 7 and 10 appear to be compatible with those reported by Vinatier et al. (2015) in the atmospheric regions probed here, bearing in mind that their limb data do not sound the lower parts of the stratosphere that contribute significantly in the 
emission we see in the nadir data, especially for the higher northern and southern latitudes (near $70^{\circ} \mathrm{N}$ and $70^{\circ} \mathrm{S}$ ). Furthermore, some of the molecules have profiles with sharp slopes and are therefore not easy to compare with our vertically constant mixing ratios here (like $\mathrm{HCN}$ and $\mathrm{C}_{4} \mathrm{H}_{2}$ ). The difference between constant-with-height and vertical profiles is all the more important in the case of strong bands like the $\mathrm{C}_{2} \mathrm{H}_{2}$ one (see Coustenis et al. 2010) and the comparison is rendered difficult there also. With all these caveats in mind and given the error bars, our findings are in general compatible with Vinatier et al.'s vertical profiles. At high northern latitudes these authors do not have data after 2011, whereas our nadir spectra are limited to 2014. At midnorthern latitudes we compare our September 2012 values with their June 2012 vertical profiles and we find compatible values within 2-3 $\sigma$ for all molecules, noting that for $\mathrm{C}_{2} \mathrm{H}_{2}, \mathrm{HC}_{3} \mathrm{~N}$ and $\mathrm{C}_{6} \mathrm{H}_{6}$ we have slightly higher values (by about $50 \%$ ). For mid-southern (close to $50^{\circ} \mathrm{S}$ ) latitudes we find our September 2012 values to be in good agreement (1-2 $\sigma$ level) with their February 2012 findings in the 0.1-6 mbar region except for $\mathrm{C}_{2} \mathrm{H}_{2}$ which we find to be two times larger. For $\mathrm{HC}_{3} \mathrm{~N}$, we have no comparison means since their profile is only inferred above $0.01 \mathrm{mbar}$ at these latitudes and they do not derive the $\mathrm{C}_{6} \mathrm{H}_{6}$ profile.

For the high southern latitudes (around $70^{\circ} \mathrm{S}$ ), the CFs of molecules such as the nitriles, $\mathrm{C}_{2} \mathrm{H}_{2}$, $\mathrm{C}_{2} \mathrm{H}_{4}, \mathrm{C}_{2} \mathrm{H}_{6}$, and $\mathrm{C}_{6} \mathrm{H}_{6}$ probe atmospheric levels as high as 0.1 mbar during earlier dates investigated here (2010-2012) and lower in later times. We have taken this into account in comparing our values with the Vinatier et al. (2015) vertical profiles at $201075^{\circ} \mathrm{S}$ from highresolution CIRS limb spectra and with the $\mathrm{HCN}$ and $\mathrm{C}_{2} \mathrm{H}_{2}$ February $20127^{\circ} \mathrm{S}$ vertical distributions at lower resolution. All in all, as far as we can tell, given the differences in resolution and possibly in latitude (their latitudes are closer to the South pole by about $10^{\circ}$ in latitude), we are quite compatible at the 3- $\sigma$ level for the high southern abundances in both dates, in spite of the very steep slopes observed for $\mathrm{C}_{2} \mathrm{H}_{4}, \mathrm{C}_{3} \mathrm{H}_{4}, \mathrm{C}_{4} \mathrm{H}_{2}$ and $\mathrm{HCN}$ in the lower levels (within a factor of 2). We find somewhat higher values for $\mathrm{C}_{2} \mathrm{H}_{4}$ and $\mathrm{C}_{3} \mathrm{H}_{8}$ in 2010. Again, with the caveats mentioned above, this is rather a good agreement between constant values and vertical distributions.

Our results are also in agreement with Moreno et al. (2014) reports from recent ALMA observations for $\mathrm{HC}_{3} \mathrm{~N}$ and $\mathrm{HCN}$ (Cordiner et al., 2014).

\section{Discussion}

Titan's south pole is rapidly evolving towards a cold stratosphere and an enhanced chemical content due to the change in seasons, similar to what is found on Earth, due to Saturn's (and hence Titan's) $26.73^{\circ}$ obliquity. The South is now the winter pole where photons are reduced and we see an increase of species due to photolysis reduction. Adding the circulation effects provides the general trend of increased abundances towards the pole, which is modulated by the different chemical lifetimes of each species.

Indeed, insights on the relative changes between the species can be found by considering their chemical time scales, as has been shown for the North (e.g. Teanby et al., 2009). The species under consideration here can be grouped into different categories according to their chemical time scales in Titan's stratosphere, calculated based on the model by Lavvas et al. (2008). At 150 $\mathrm{km}$ in altitude, the longest-lived molecules are $\mathrm{CO}_{2}\left(10^{12} \mathrm{~s}\right), \mathrm{C}_{2} \mathrm{H}_{6}$ and $\mathrm{C}_{3} \mathrm{H}_{8}\left(\right.$ at $\left.7-8 \times 10^{10} \mathrm{~s}\right), \mathrm{HCN}$ $\left(10^{9} \mathrm{~s}\right)$ and $\mathrm{C}_{2} \mathrm{H}_{2}\left(2 \times 10^{8} \mathrm{~s}\right)$. They are followed by shorter-lived species like $\mathrm{C}_{3} \mathrm{H}_{4}\left(7 \times 10^{7} \mathrm{~s}\right), \mathrm{C}_{2} \mathrm{H}_{4}$ and $\mathrm{HC}_{3} \mathrm{~N}$ (at about $\left.3 \times 10^{7} \mathrm{~s}\right), \mathrm{C}_{4} \mathrm{H}_{2}\left(6 \times 10^{6} \mathrm{~s}\right)$ and $\mathrm{C}_{6} \mathrm{H}_{6}\left(3 \times 10^{6} \mathrm{~s}\right)$. At $250 \mathrm{~km}$ in altitude, the lifetimes are generally shorter for all the molecules, with the longest ones for $\mathrm{CO}_{2}\left(3 \times 10^{10} \mathrm{~s}\right), \mathrm{C}_{2} \mathrm{H}_{6}$ $\left(10^{10} \mathrm{~s}\right), \mathrm{C}_{3} \mathrm{H}_{8}\left(7 \times 10^{9} \mathrm{~s}\right), \mathrm{HCN}\left(2 \times 10^{9} \mathrm{~s}\right)$ and $\mathrm{C}_{2} \mathrm{H}_{2}\left(4 \times 10^{7} \mathrm{~s}\right)$. The shorter-lived species have 
lifetimes as follows: $\mathrm{C}_{3} \mathrm{H}_{4}\left(10^{7} \mathrm{~s}\right), \mathrm{C}_{2} \mathrm{H}_{4}\left(7 \times 10^{6} \mathrm{~s}\right)$ and $\mathrm{HC}_{3} \mathrm{~N}\left(2 \times 10^{6} \mathrm{~s}\right)$, and $\mathrm{C}_{4} \mathrm{H}_{2}$ and $\mathrm{C}_{6} \mathrm{H}_{6}$ (at about $4 \times 10^{5} \mathrm{~s}$ ). Most of the longest-lived species (in order : $\mathrm{CO}_{2}, \mathrm{C}_{2} \mathrm{H}_{6}, \mathrm{C}_{3} \mathrm{H}_{8}, \mathrm{HCN}$, and $\mathrm{C}_{2} \mathrm{H}_{2}$ ) are then also among the most abundant ones (in order: $\mathrm{C}_{2} \mathrm{H}_{6}, \mathrm{C}_{2} \mathrm{H}_{2}, \mathrm{C}_{3} \mathrm{H}_{8}, \mathrm{C}_{2} \mathrm{H}_{4}$ and $\mathrm{HCN}$ ) in Titan's stratosphere, with the exception of $\mathrm{CO}_{2}$. But $\mathrm{CO}_{2}$ is produced from $\mathrm{CO}$ that is almost inert and well mixed in the atmosphere, probably horizontally as well. This could explain at least partly (because other processes like dynamics and circulation are also at play) the lack of important changes with time since 2010 or in the past year for some of these species, with the exception of $\mathrm{HCN}$ for which a large enhancement is observed at $70^{\circ} \mathrm{S}$. From the $\mathrm{CF}$ plots (Fig. 4) $\mathrm{HCN}$ appears to be probing higher altitudes with time. So that if the HCN profile over the pole is not constant but increasing with height with a steep slope above $300 \mathrm{~km}$ (as suggested by Vinatier et al., 2015 from limb observations up to 2012), the retrieved abundance might reflect this but it is not the unique interpretation as the temperature is also increasing with altitude and time also.

Since the stratospheric lifetime of a species measures the time required to restore equilibrium following a sudden increase or decrease in its concentration, it is then normal that the less-abundant and more short-lived species, more dependent on photolysis, exhibit abundances increasing towards the winter southern pole, where photons are reduced, due to the minimization of the photolysis. This, along with the circulation pattern leads to the increase in the abundances observed for $\mathrm{C}_{2} \mathrm{H}_{4}, \mathrm{C}_{3} \mathrm{H}_{4}, \mathrm{C}_{4} \mathrm{H}_{2}, \mathrm{C}_{6} \mathrm{H}_{6}$ and $\mathrm{HC}_{3} \mathrm{~N}$. Whereas the northern latitudes have yet to show important changes at $50^{\circ}$ and above in latitude, the south exhibits dramatic variations in the past 4 years or so. This affects also HCN, which - while stable at all other high northern or southern latitudes up to $50^{\circ} \mathrm{S}$-, shows a large increase near the southern pole.

Another way to envisage the situation is through the photolysis rates: if we neglect the circulation effects, the species that will be mostly affected by the lack of photolysis close to the south pole are those for which the photolysis has a major role in their loss rates. For $\mathrm{C}_{2} \mathrm{H}_{6}, \mathrm{C}_{3} \mathrm{H}_{8}$, and $\mathrm{CO}_{2}$ and to a lesser degree for $\mathrm{HCN}$, photolysis is less important than it is for $\mathrm{C}_{4} \mathrm{H}_{2}, \mathrm{HC}_{3} \mathrm{~N}$ or $\mathrm{C}_{6} \mathrm{H}_{6}$, hence the more dramatic changes in the South for the latter two molecules.

For a global view and interpretation of these results, photochemical models would need to add dynamics. The $50^{\circ} \mathrm{S}$ and $70^{\circ} \mathrm{S}$ abundances have a clearly different trend for all species. The former present a slow increase with time, while the latter demonstrate a sharp increase. These two regions demonstrate the different dynamics in and out of the vortex region. This trend is confirmed in other studies (Bampasidis et al. 2012; Vinatier et al. 2015). The sharp decrease in temperature observed already in 2012 over the South pole (Teanby et al. 2012; Vinatier et al. 2015) is confirmed here and found to persist even more dramatically in recent years. It is linked to the enrichment of the pole in gases and condensates which cause radiative cooling, for which we show here that the progress is also quite extensive in the past two years. The reversal in the global circulation in Titan's atmosphere is confirmed by our data.

Vinatier et al. (2005), and references within, find their results to be indicative of two circulation cells co-existing causing upwelling at mid-latitudes and downwelling at both poles during 2010. These then become a single pole-to-pole cell upwelling at the north pole and downwelling at the south pole after the reversal in 2011 with the ascending branch at the north pole bringing the enriched air accumulated during the northern winter towards mid-latitudes at high altitude. We find that the ensuing south polar temperature decrease and chemical enhancement dramatically increases after 2012, especially for some species. Observations indicate that the evolution of the enhancement in atmospheric species in the South is strongly dependent on the altitude, starting at high levels and then extending deeper into the stratosphere and diffusing from the pole towards mid latitudes. We have evidence in this work that the effects are visible also at the altitudes and latitudes we probe here : at $50^{\circ} \mathrm{S}$ some species like $\mathrm{C}_{3} \mathrm{H}_{8}, \mathrm{C}_{6} \mathrm{H}_{6}$ and $\mathrm{HC}_{3} \mathrm{~N}$ show the enhancement with time after 2013. 
Similarly to the haze and other gaseous abundance increases in the south reported previously (Jennings et al., 2012b; Teanby et al., 2012), the rather quick increase of HCN and more dramatically of $\mathrm{HC}_{3} \mathrm{~N}$ is thus probably also linked to the deepening polar shadow and the decreasing stratospheric temperatures as the season changes. As winter sets in the south, the higher chemical formation altitudes remain in perpetual sunlight while the polar shadow lower down in the stratosphere shields the gases and allows them to accumulate (Yung, 1987). The evolution observed by CIRS is consistent with this polar shadowing as pointed out by Jennings et al., (2012b). In 2012 the South pole was in darkness, possibly at high altitudes, an effect which promotes stratospheric cooling and chemical enhancement of the kind observed previously at high northern latitudes by Cassini CIRS, by Cassini radio occultations and by Voyager/IRIS (Achterberg et al., 2008a, 2011; Coustenis et al., 1991, 2007, 2010; Schinder et al., 2012). During winter the northern stratospheric temperatures were lower by $20-40 \mathrm{~K}$ with respect to equatorial temperatures. Our $\mathrm{CFs}$ for the nitriles $\mathrm{HCN}$ and $\mathrm{HC}_{3} \mathrm{~N}$ are showing that the pressure levels sounded in recent years had raised from around 100 to around $250-300 \mathrm{~km}$. Jennings et al., (2012a) note that the decrease in the stratospheric temperatures, as found now at the south pole, causes the nitrile condensation altitude to raise from $\sim 90 \mathrm{~km}$ to $\sim 150-170 \mathrm{~km}$, consistent with the height of the $\mathrm{HC}_{3} \mathrm{~N}$ feature. We find here that the emission seen in the spectra follows this trend and therefore we continue throughout time to probe levels where the condensation occurs. At even higher altitudes (close to $300 \mathrm{~km}$ ) and over the south pole, Cassini observations witnessed the formation and evolution of a cloud structure with composition consistent with HCN ice (de Kok et al., 2014, West et al., 2015). The cloud is localized within 10 degrees of the atmospheric tilted south pole and probably resulted from the combination of the increased nitrile abundances and low local temperatures that we find here.

In the stratosphere, as probed by CIRS nadir data, nitriles began to build-up before the onset of the $220 \mathrm{~cm}^{-1}$ emission (Jennings et al., 2012b). $\mathrm{HC}_{3} \mathrm{~N}$ is present in September 2011 spectra but not in June 2011 spectra, suggesting that the nitrile increase began in late 2011, about a year before the $220 \mathrm{~cm}^{-1}$ feature was first seen. This evidence, together with the observed trend for decrease in most species during winter to spring in the north (Bampasidis et al., 2012; Jennings et al., 2012a; Vinatier et al., 2015), indicates that changes in the haze and changes in the molecular abundance are probably related. Our results are consistent with the suggestion that condensed nitriles contribute to the far-infrared haze (Coustenis et al., 1999; Dello Russo \& Khanna 1996; Khanna 2005; de Kok 2008, Jennings et al., 2012a).

Since we now have some recent exploitable data at $70^{\circ} \mathrm{N}$, we perform a comparison with Voyager/IRIS inferences at $70^{\circ} \mathrm{N}$, at a similar epoch. From vertical distributions inferred from 1980 data, we find the values at our probed regions to be about $3 \times 10^{-8}$ for $\mathrm{C}_{4} \mathrm{H}_{2}$ and $\mathrm{C}_{3} \mathrm{H}_{4}, 5 \times 10^{-8}$ for $\mathrm{HC}_{3} \mathrm{~N}$ and $10^{-6}$ for $\mathrm{HCN}$ (Coustenis et al., 1991). These values, when compared to our 2014 ones at $70^{\circ} \mathrm{N}$ (black lines in Fig. 10), are quite similar for all these molecules except for $\mathrm{HC}_{3} \mathrm{~N}$, where they are slightly higher. Given the possible uncertainties arising from important differences between the two datasets and the 4 years apart in epoch time (the exact one Titanian year time after V1 was in 2010), this indicates that our results for $70^{\circ} \mathrm{N}$ are quite compatible after one Titanian year in terms of chemical content and no significant inter-annual variations for these molecules at these latitudes is expected. A similar result was reported for $50^{\circ} \mathrm{N}$ in Coustenis et al. (2013). The differences found for the two complex hydrocarbons $\mathrm{C}_{4} \mathrm{H}_{2}$ and $\mathrm{C}_{3} \mathrm{H}_{4}$ at that latitude do not seem to be significant at $70^{\circ} \mathrm{N}$.

Until the end of the Cassini mission foreseen in 2017, CIRS will continue to observe changes in the north and south. We will thus be able to continue to monitor the gaseous and haze content in the atmosphere along with the temperature changes. By allowing us to observe the atmospheric evolution in both hemispheres with better coverage for almost one-half of a Titan year, the 
Cassini-Huygens mission and its predecessors are providing scientists with a unique opportunity to predict what the seasonal effects are on this complex body.

\section{Acknowledgements}

We acknowledge support from NASA's Cassini mission, Cassini Data Analysis Program and Planetary Astronomy Program. AC acknowledges financial support from the French "Agence Nationale de la Recherche" (ANR Project: “APOSTIC" \#11BS56002), France. We also thank the data processing team in Meudon and especially Florence Henry, and the planning and processing team at Goddard, in particular Nicolas Gorius and Marcia Segura.

\section{References}

Achterberg, R.K., Conrath, B.J., Gierasch, P.J., Flasar, F.M., Nixon, C.A., 2008a. Titan's middleatmospheric temperatures and dynamics observed by the Cassini Composite Infrared Spectrometer. Icarus 194, 263-277.

Achterberg, R.K., Conrath, B.J., Gierasch, P.J., Flasar, F.M., Nixon, C.A., 2008b. Observation of a tilt of Titan's middle-atmospheric superrotation. Icarus 197, 549-555.

Achterberg, R.K., Gierasch, P.J., Conrath, B.J., Flasar, F.M., Nixon, C.A., 2011. Temporal variations of Titan's middle-atmospheric temperatures from 2004 to 2009 observed by Cassini/CIRS. Icarus 211, 686-698.

Anderson, C.M., Samuelson, R.E., 2011. Titan's aerosol and stratospheric ice opacities between 18 and $500 \mu \mathrm{m}$ : Vertical and spectral characteristics from Cassini CIRS. Icarus 212, 762778.

Bézard, B., 2014. The methane mole fraction in Titan's stratosphere from DISR measurements during the Huygens probe's descent. Icarus 242, 64-73.

Bampasidis, G., Coustenis, A., Achterbergh, R. K., Vinatier, S., Lavvas, P., Nixon, C. A., Jennings, D. E., Teanby, N. A., Flasar, F. M., Carlson, R. C., Mousas, X., Preka-Papadema, P., Romani, P. N., Guardique, E. A., Stamogiorgos, S., 2012. Thermal and temperature structure variations in Titan's stratosphere during the Cassini mission. Astroph. J. 760, Issue 2, article id. 144, 8pp.

Cordiner, M. A., Nixon, C. A., Teanby, N. A., Irwin, P. G. J., Serigano, J., Charnley, S. B., Milam, S. N., Mumma, M. J., Lis, D. C., Villanueva, G., Paganini, L., Kuan, Y.-J., Remijan, A. J., 2014. ALMA Measurements of the $\mathrm{HNC}$ and $\mathrm{HC}_{3} \mathrm{~N}$ Distributions in Titan's Atmosphere. Astroph. J. Lett. 795, L30, 6pp.

Coustenis, A., Bézard, B., Gautier, D., Marten, A. Samuelson, R., 1991. Titan's Atmosphere from Voyager Infrared Observations: III. The vertical distributions of hydrocarbons and nitriles near Titan's North Pole. Icarus 89, 152-167.

Coustenis, A., Schmitt, B., Khanna, R., Trotta, F., 1999. Plausible condensates in Titan's stratosphere from Voyager IR spectra. Plan. Space Sci, 47, 1305-1329.

Coustenis, A., Achterberg, R.K., Conrath, B.J., Jennings, D.E., Marten, A., Gautier, D., Nixon, C.A., Flasar, F.M., Teanby, N.A., Bézard, B., Samuelson, R.E., Carlson, R.C., Lellouch, E., Bjoraker, G.L., Romani, P.N., Taylor, F.W., Irwin, P.G.J., Fouchet, T., Hubet, A., Orton, G.S., Kunde, V.G., Vinatier, S., Mondellini, J., Abbas, M.M., Courtin, R., 2007. The 
composition of Titan's stratosphere fromGlenn Cassini/CIRS mid-infrared spectra. Icarus $189,35-62$.

Coustenis, A., Jennings, D. E., Nixon, C. A., Achterbergh, R. K., Lavvas, P., Vinatier, S., Teanby, N. A., Bjoraker, G. L., Carlson, R. C., Piani, L., Bampasidis, G., Flasar, F. M., Romani, P. N., 2010. Titan trace gaseous composition from CIRS at the end of the CassiniHuygens prime mission. Icarus 207, 461-476. http://dx.doi.org: 0.1016/j.icarus.2009.11.027.

Coustenis, A., Bampasidis, G., Achterberg, R. K., et al., 2013. "Evolution of the stratospheric temperature and chemical composition over one titanian year. Astroph. J. 779, 177.

de Kok, R., Irwin, P. G. J., Teanby, N. A. 2008. Condensation in Titan's stratosphere during polar winter. Icarus 197, 572-578.

de Kok, R.J., Teanby, N.A., Maltagliati, L., Irwin, P.G.J., Vinatier, S., 2014. HCN ice in Titan's high-altitude southern polar cloud. Nature 514, 65-67.

Dello Russo, N., Khanna, R. K., 1996. Laboratory Infrared Spectroscopic Studies of Crystalline Nitriles with Relevance to Outer Planetary Systems. Icarus 123, 366-395.

Jennings, D. E., Anderson, C. M., Samuelson, R. E., Flasar, F. M., Nixon, C. A., Kunde, V. G., Achterberg, R. K., Cottini, V., de Kok, R., Coustenis, A., Vinatier, S., Calcutt, S. B., 2012 a. Seasonal Disappearance of Far-infrared Haze in Titan's Stratosphere. Astrophys. J. Lett. 754:L3, 4pp.

Jennings, D. E., Anderson, C. M., Samuelson, R. E., Flasar, F. M., Nixon, C. A., Bjoraker, G. L., Romani, P. N., Achterberg, R. K., Cottini, V., Hesman, B. E., Kunde, V. G., Carlson, R. C., de Kok, R., Coustenis, A., Vinatier, S., Bampasidis, G., Teanby, N. A., Calcutt, S. B., 2012 b. First Observation in the South of Titan's Far-infrared $220 \mathrm{~cm}^{-1}$ Cloud. Astrophys. J. Lett. 761:L15, 4pp.

Jennings, D., Achterberg, R. K., Cottini, V., Anderson, C. M., Flasar, F. M., Nixon, C. A., Bjoraker, G. L., Kunde, V. G., Carlson, R. C., Guandique, E., Kaelberer, M.S., Segura, M.E., de Kok, R., Coustenis, A., Vinatier, S., Bampasidis, G., Teanby, N. A., Calcutt, S. B., 2015. Evolution of the far-infrared ice cloud at Titan's South pole. Astrophys. J. Lett. 804:L34, $5 \mathrm{pp}$.

Hayes, A.G., Aharonson, O., Callahan, P., Elachi, C., Gim, Y., Kirk, R., Lewis, K., Lopes, R., Lorenz, R., Mitchell, K., Mitri, G., Stofan, E., Wall, S., 2008. Hydrocarbon lakes on Titan: Distribution and interaction with a porous regolith. Geoph. Res. Let. 35, L09204

Khanna, R.K. 2005. Condensed species in Titan's stratosphere: Confirmation of crystalline cyanoacetylene $\left(\mathrm{HC}_{3} \mathrm{~N}\right)$ and evidence for crystalline acetylene $\left(\mathrm{C}_{2} \mathrm{H}_{2}\right)$ on Titan. Icarus 178 , 165-170.

Lavvas, P. P., Coustenis, A., Vardavas, I. M., 2008. Coupling photochemistry with haze formation in Titan's atmosphere. Part I: Model description. Plan. Space Sci. 56, 27-66.

Lavvas, P., Sander, M., Kraft, M., Imanaka, H., 2011. Surface Chemistry and Particle Shape: Processes for the Evolution of Aerosols in Titan's Atmosphere. Astroph. J. 728, 80, 11 pp.

Moreno et al 2014,"ALMA observations of Titan" American Astronomical Society, DPS meeting \#46, \#211.19

Niemann, H.B., Atreya, S.K., Demick, J.E., Gautier, D., Haberman, J.A., Harpold, D.N., Kasprzak, W.T., Lunine, J.I., Owen, T.C., Raulin, F., 2010. Composition of Titan's lower atmosphere and simple surface volatiles as measured by the Cassini-Huygens probe gas chromatograph mass spectrometer experiment. J. Geophys. Res. 115, E12.

Schinder, P.J., Flasar, F.M., Marouf, E.A., French, R.G., McGhee, C.A., Kliore, A.J., Rappaport, N..J. Barbinis, E., Fleischman, D., Anabtawi, A., 2012. The structure of Titan's atmosphere from Cassini radio occultations: Occultations from the Prime and Equinox missions. Icarus 221, 2, 1020-1031. 
Teanby, N.A., Irwin, P.G.J., de Kok, R., Nixon, C.A., 2009. Dynamical implications of seasonal and spatial variations in Titan's stratospheric composition. Phil. Trans. R. Soc. A 367, 697711.

Teanby N.A., Irwin, P.G.J., de Kok, R., Nixon, C.A., 2010. Seasonal Changes in Titan's Polar Trace Gas Abundance Observed by Cassini. Astroph. J. Lett. 724, L84-L89.

Teanby, N. A., Irwin, P. G. J., Nixon, C. A. de Kok, R., Vinatier, S., Coustenis, A., SeftonNash, E., Calcutt, S. B., Flasar, F. M., 2012. Active upper-atmosphere chemistry and dynamics from polar circulation reversal on Titan. Nature 491, 732-735.

Vinatier, S., Rannou, P., Anderson, C.M., Bézard, B., de Kok, R., Samuelson, R.E., 2012. Optical constants of Titan's stratospheric aerosols in the $70-1500 \mathrm{~cm}^{-1}$ spectral range constrained by Cassini/CIRS observations. Icarus 219, 5-12.

Vinatier, S., Bézard, S., Lebonnois, S., Teanby, N.A., Achterberg, R.K., Gorius, N., Mamoutkine, A., Guandique, E., Jolly, A., Jennings, D.E., Flasar, F.M., 2015. Seasonal variations in Titan's middle atmosphere during the northern spring derived from Cassini/CIRS observations. Icarus 250, 95-115.

West, R.A. et al., 2011. The evolution of Titan's detached haze layer near equinox in 2009. Geophys. Res. Let. 38, L06204, 4 pp. http://dx.doi.org/10.1029/2011GL046843.

West, R.A., Del Genio, A.D., Barbara, J.M., Toledo, D., Lavvas, P., Rannou, P., Turtle, E.P., Perry, J., 2015. Cassini Imaging Science Subsystem observations of Titan's south polar cloud. Icarus in press. http://dx.doi.org/10.1016/j.icarus.2014.11.038

Yung, Y.L., 1987. An update of nitrile photochemistry on Titan. Icarus 72, 468. 


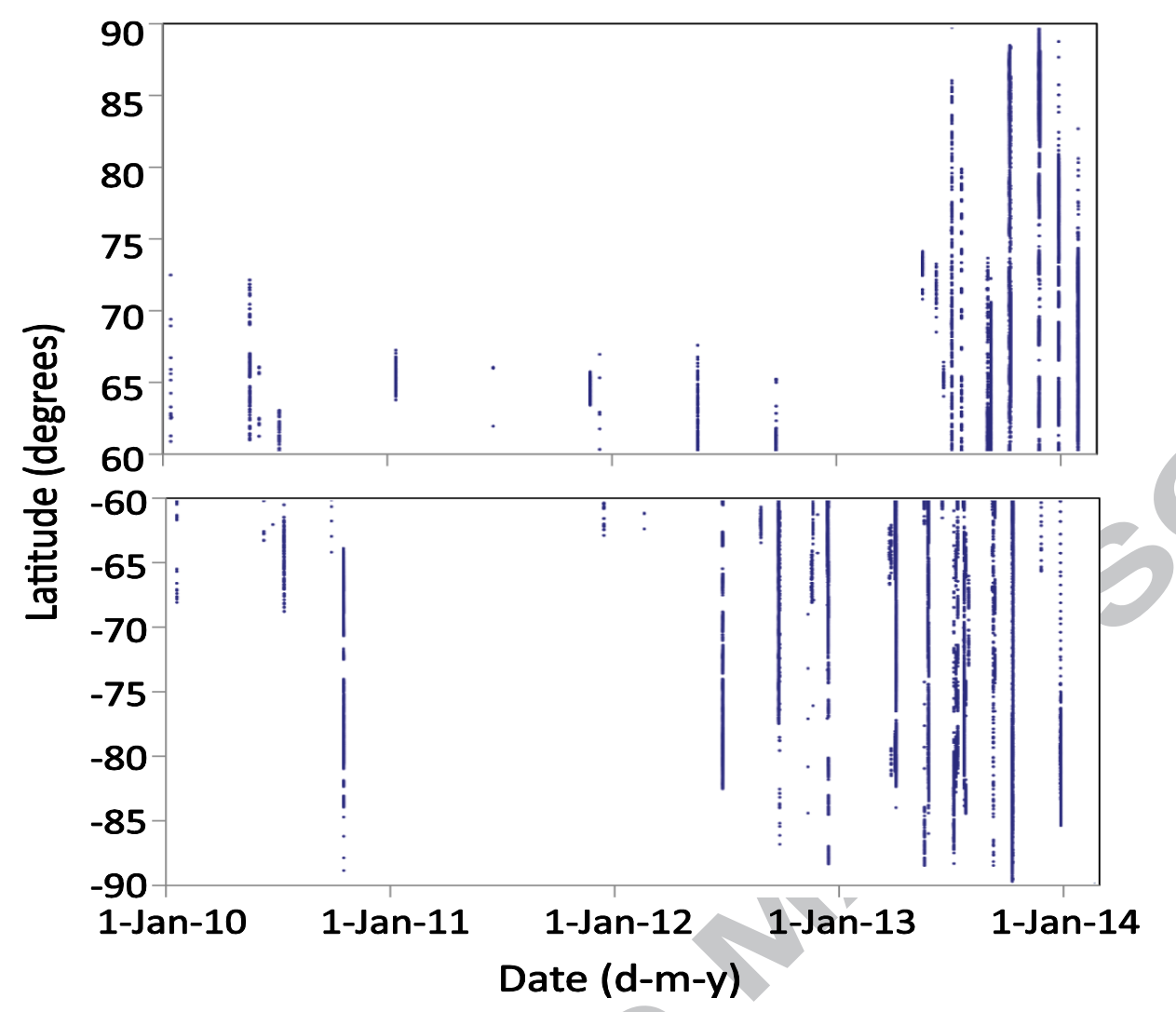




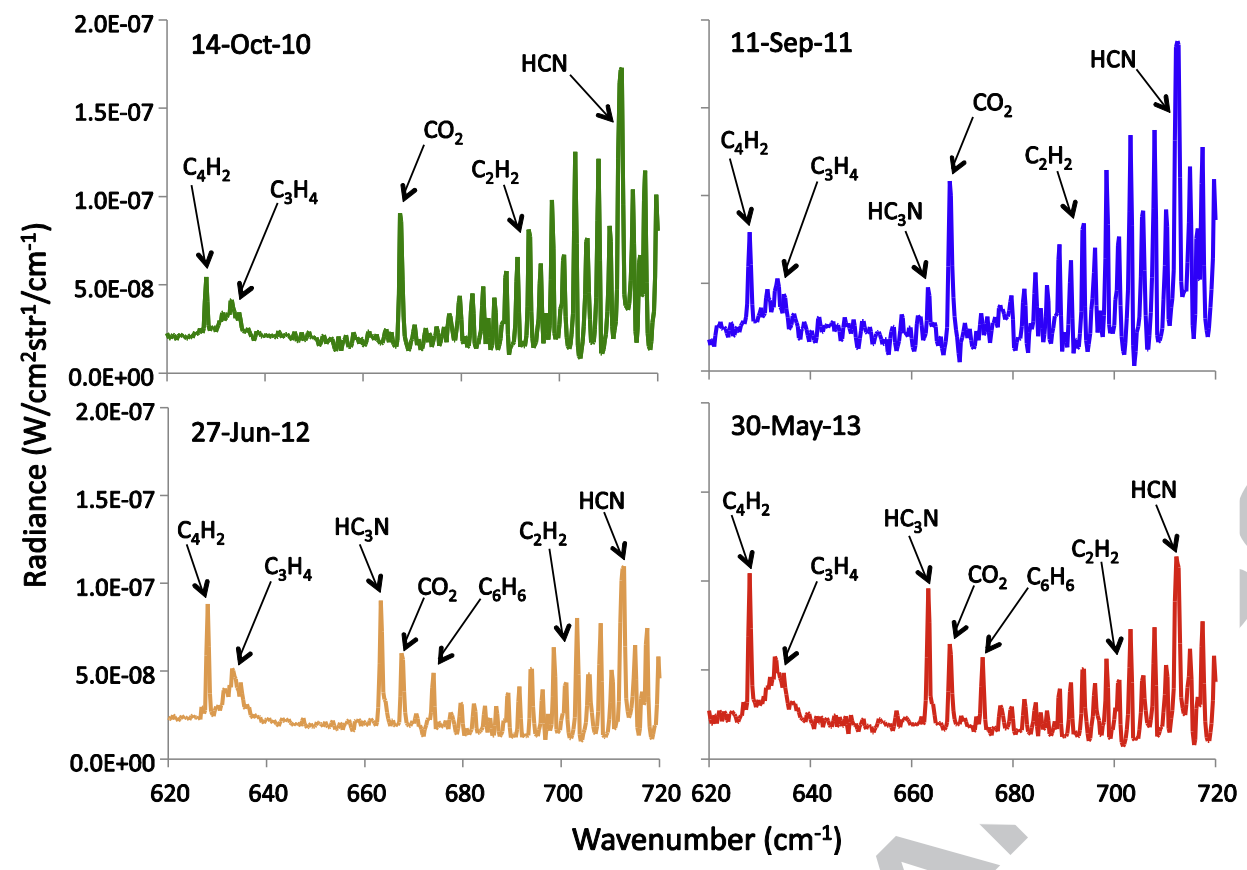



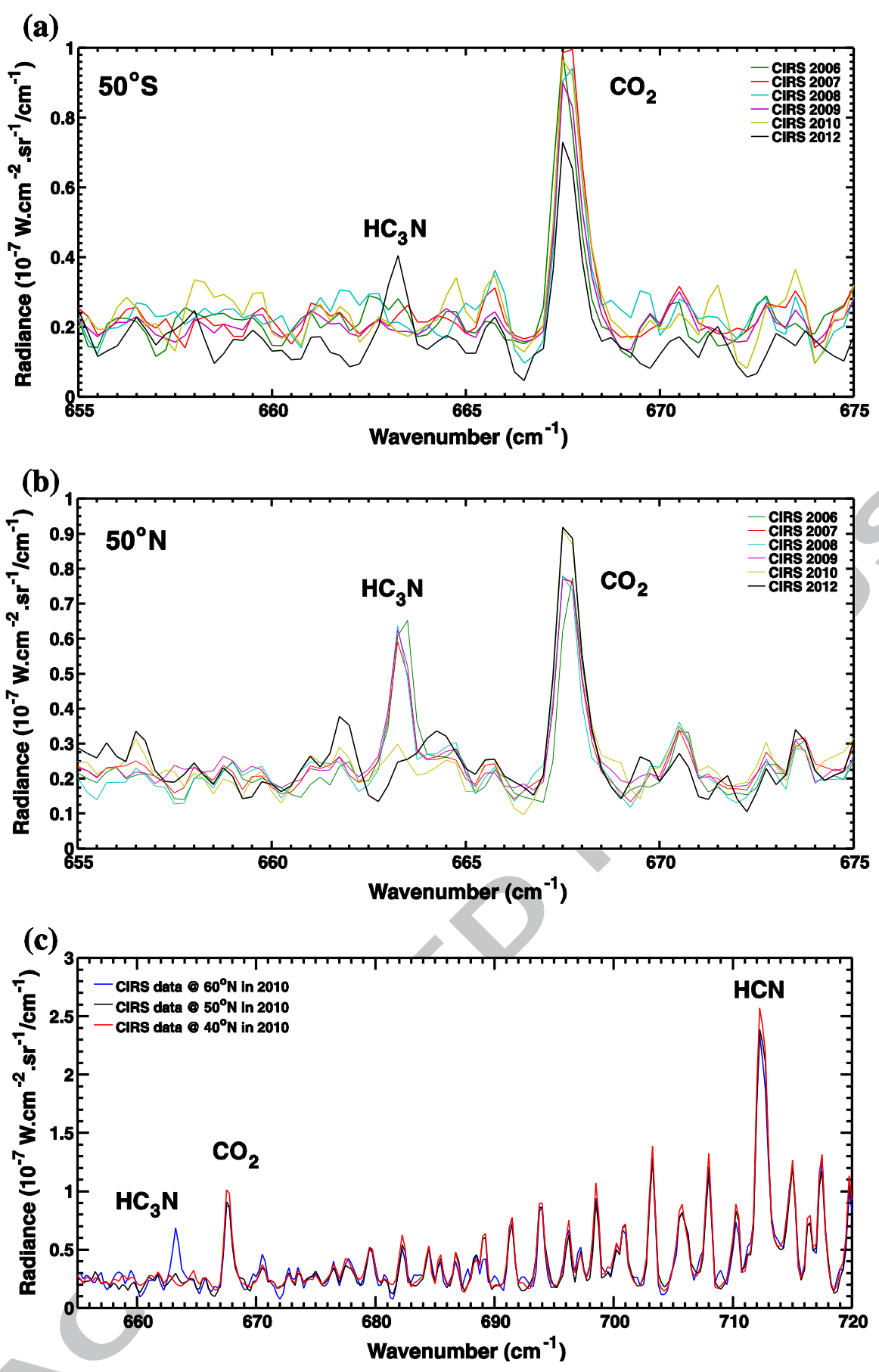

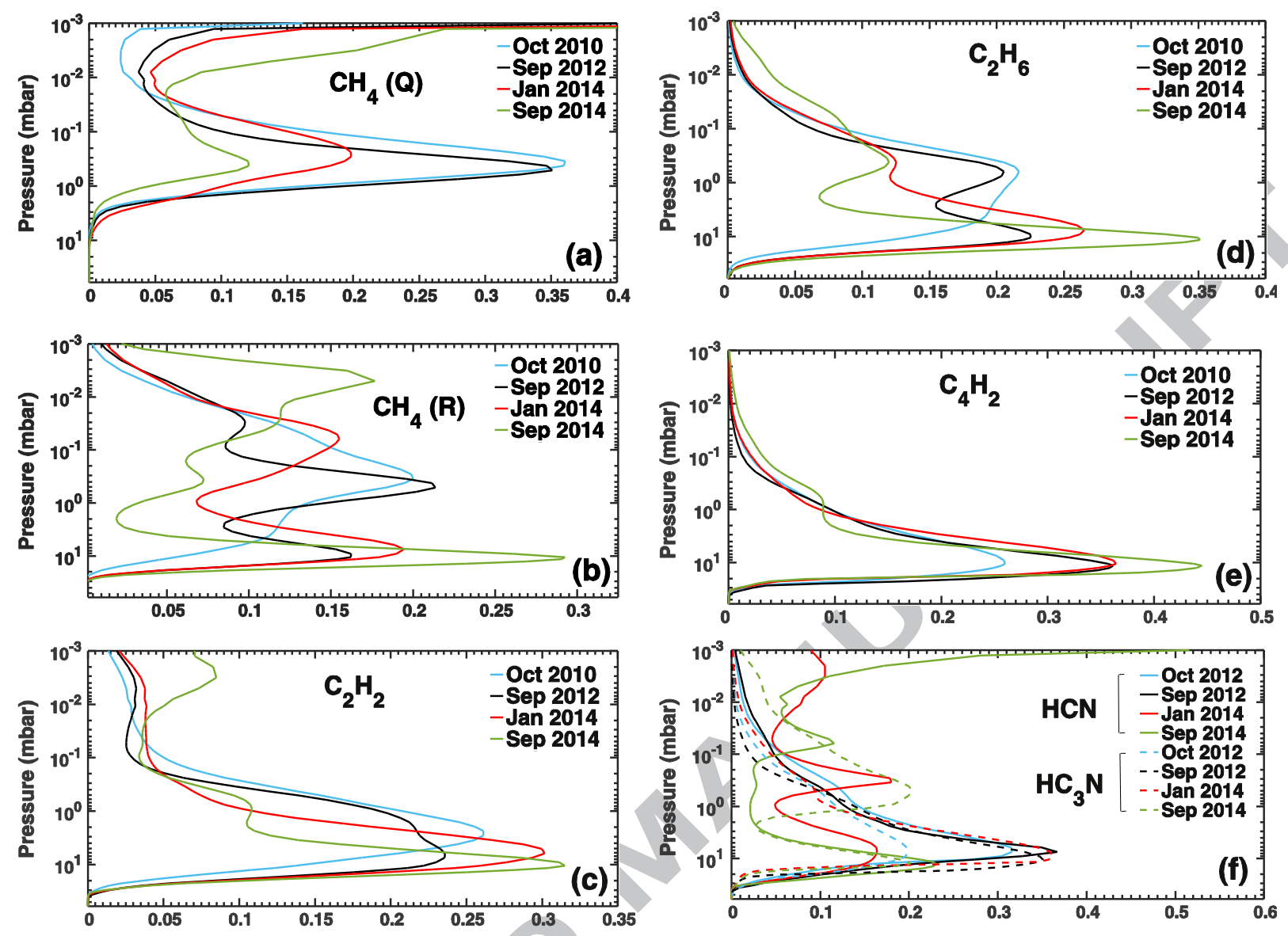

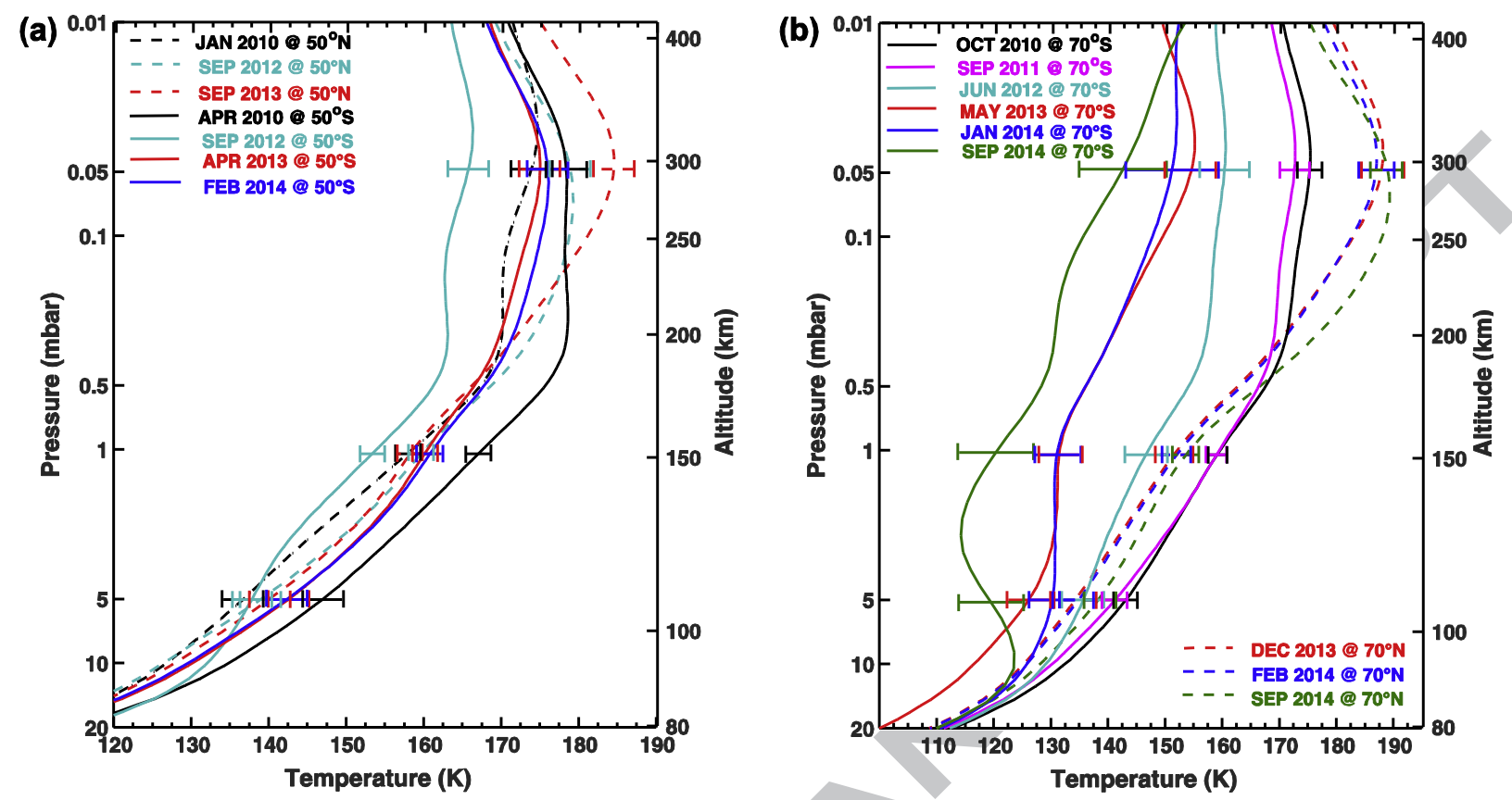

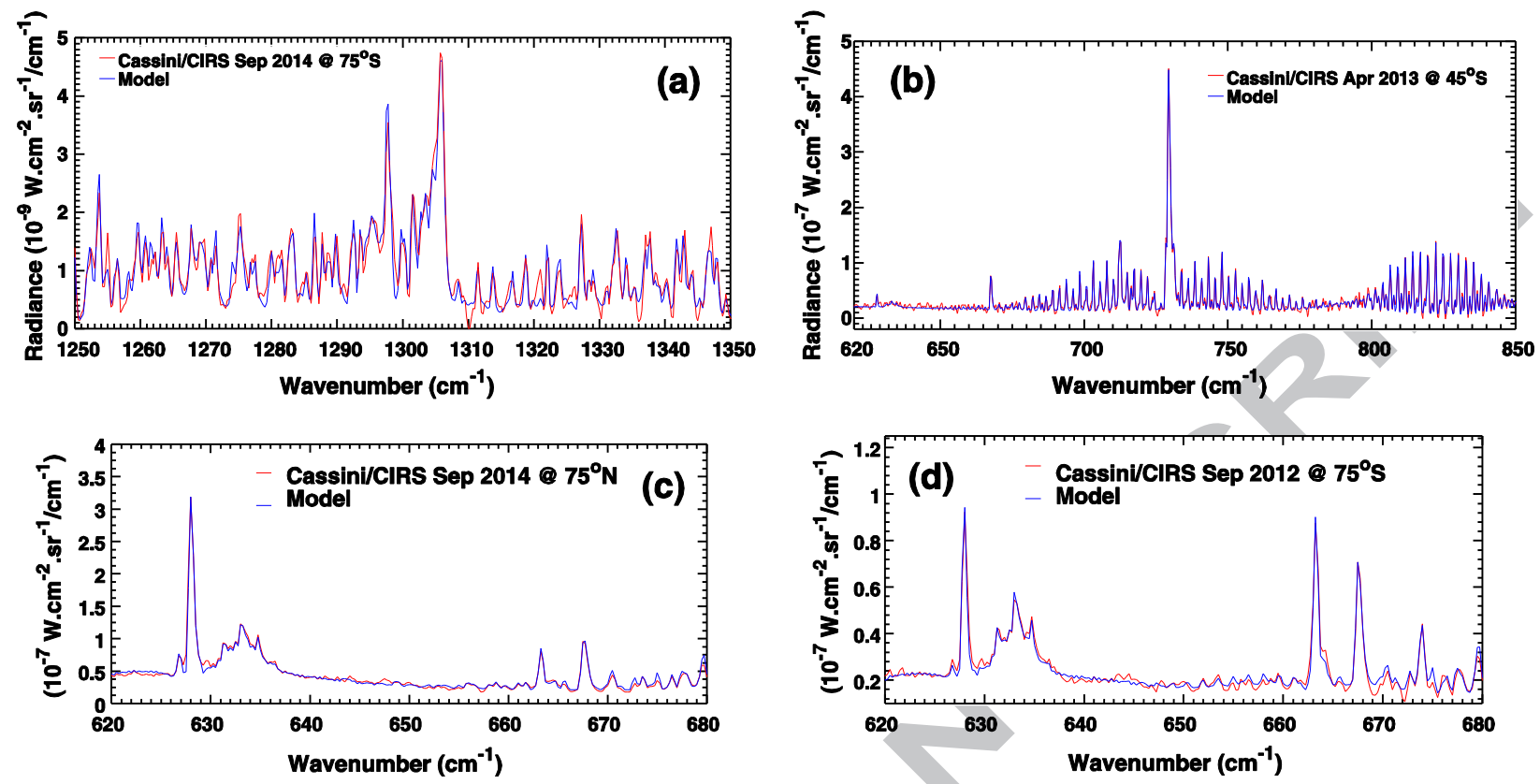

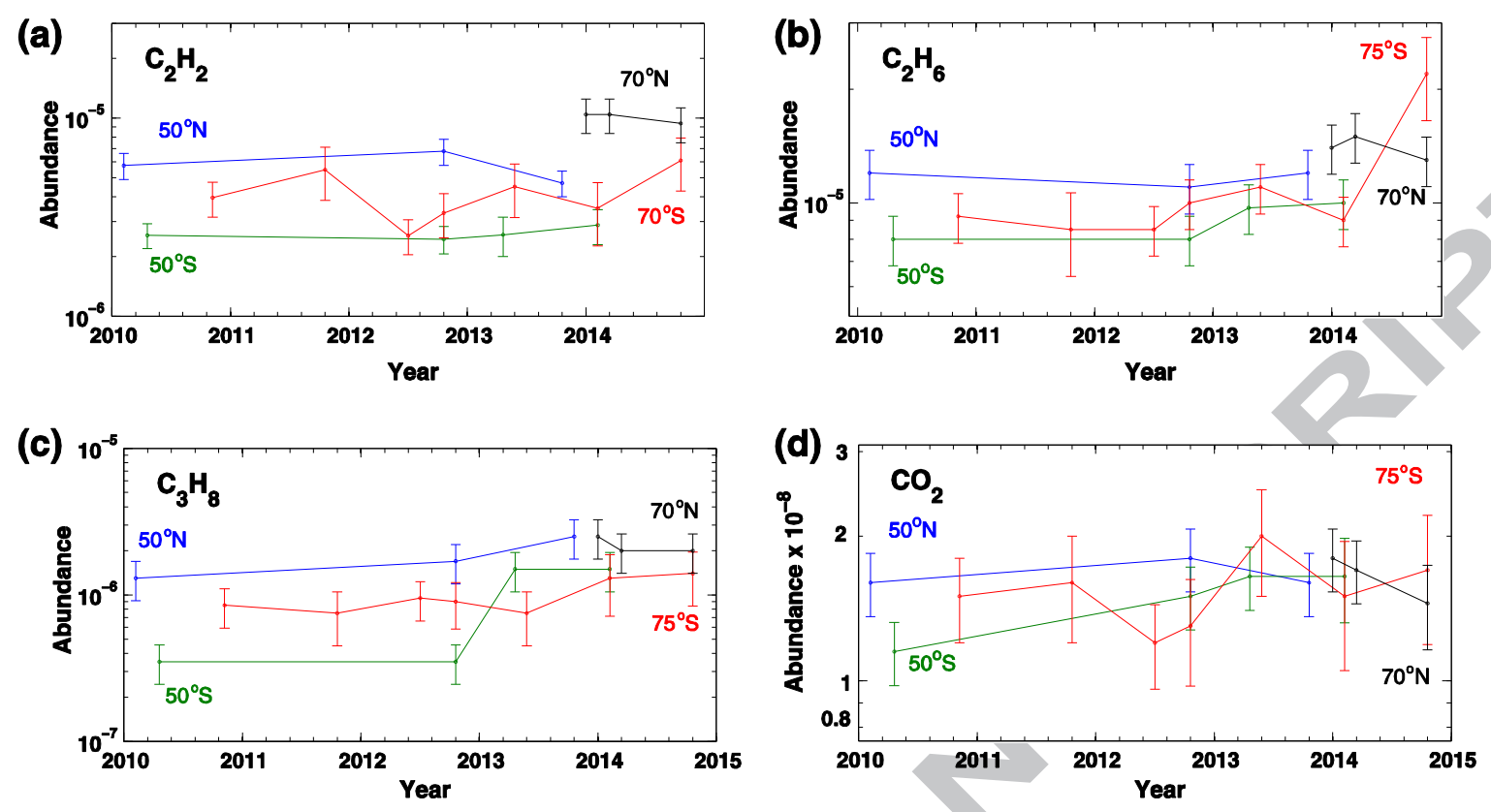


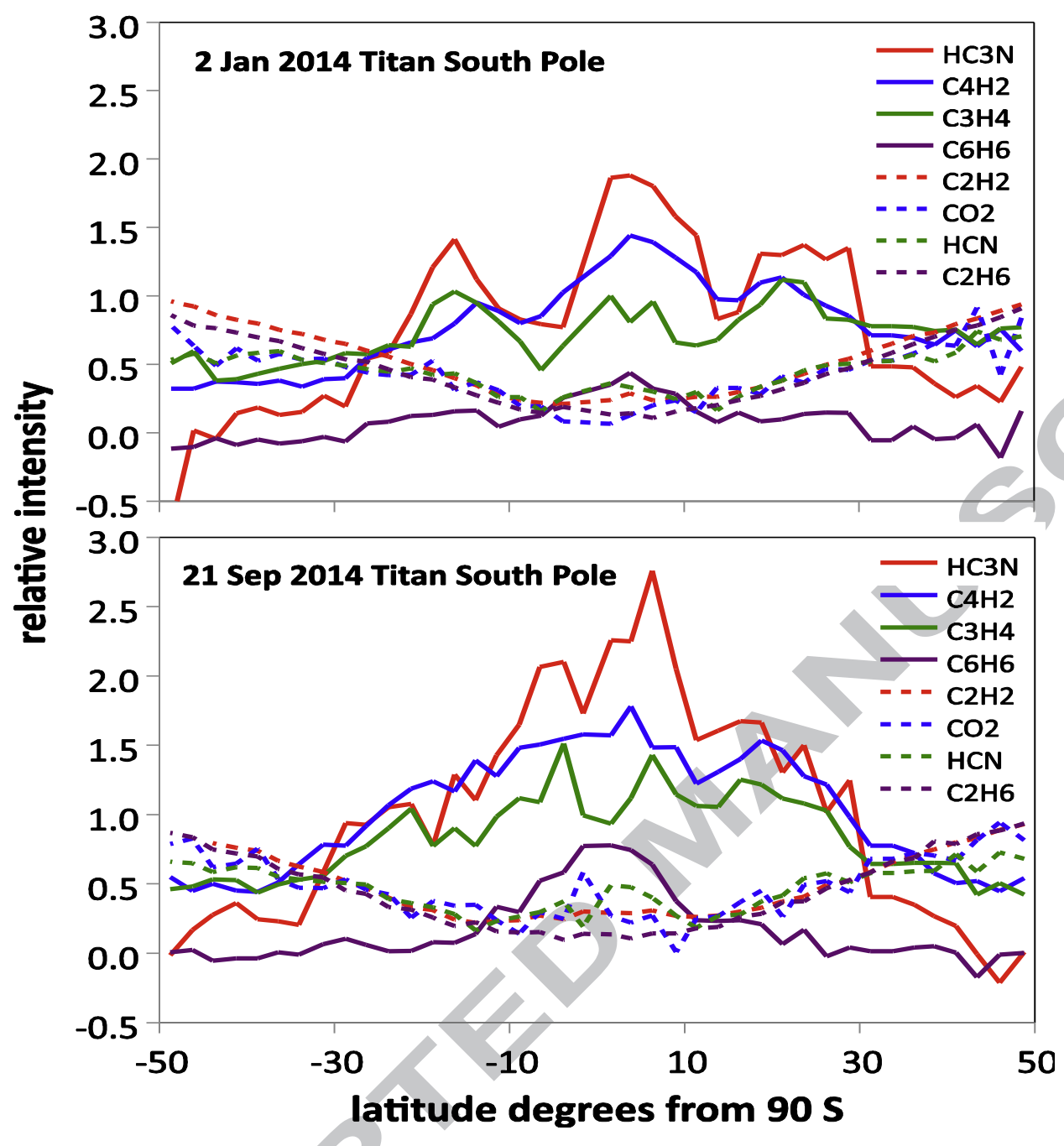



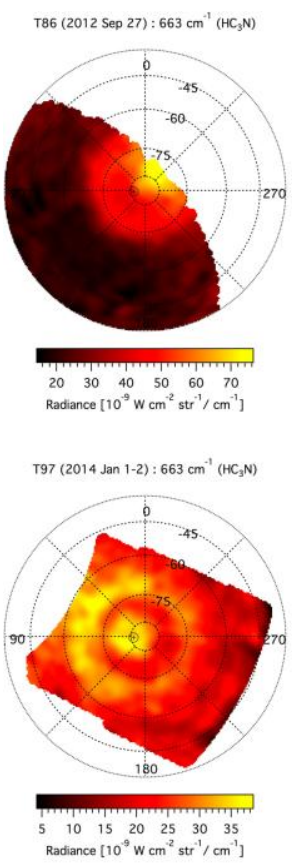

T102 (2014 Jun 17) : $663 \mathrm{~cm}^{-1}\left(\mathrm{HC}_{3} \mathrm{~N}\right)$

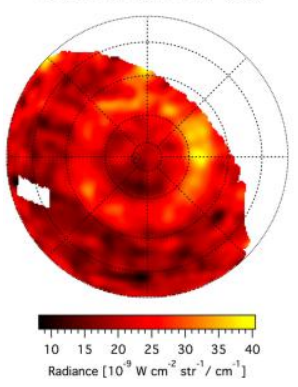

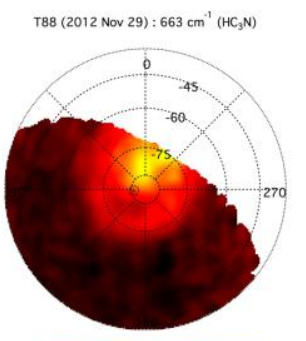

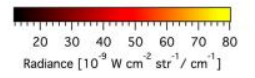

T98 (2014 Feb 2-3) : $663 \mathrm{~cm}^{-1}\left(\mathrm{HC}_{3} \mathrm{~N}\right)$

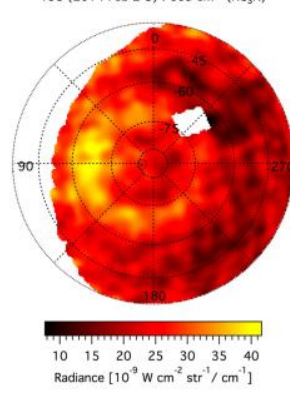

T103 (2014 Jul 19) : $663 \mathrm{~cm}^{-1}$ (HC,N)

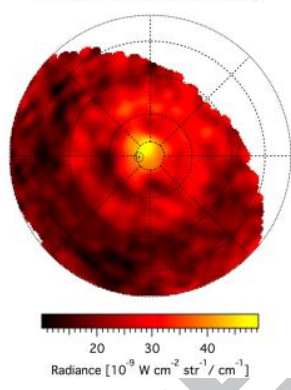

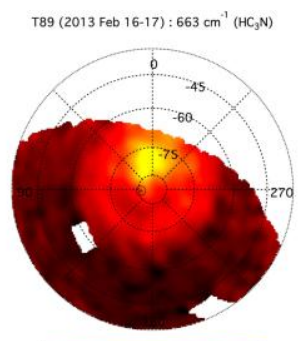
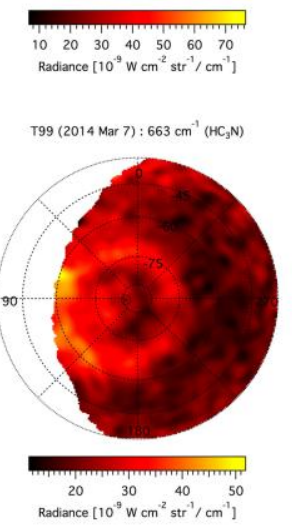

T104 (2014 Aug 20) : $663 \mathrm{~cm}^{-1}\left(\mathrm{HC}_{3} \mathrm{~N}\right)$

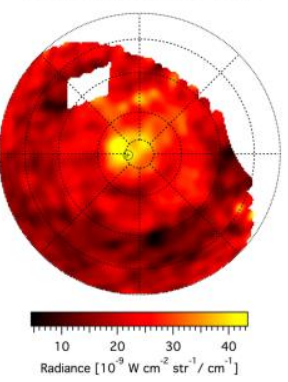

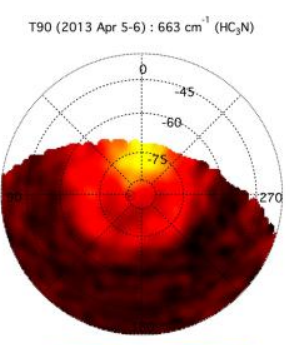

$\begin{array}{llllll}20 & 30 & 40 & 50 & 60 & 70\end{array}$

T100 (2014 Apr 6/8) : $663 \mathrm{~cm}^{-1}\left(\mathrm{HC}_{3} \mathrm{~N}\right)$
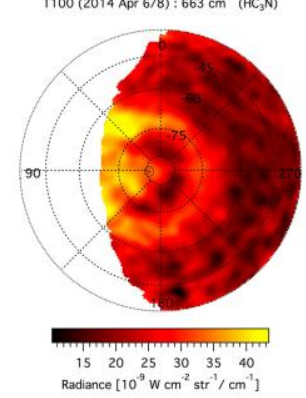

T105 (2014 Sep 21) : $663 \mathrm{~cm}^{-1}\left(\mathrm{HC}_{3} \mathrm{~N}\right)$

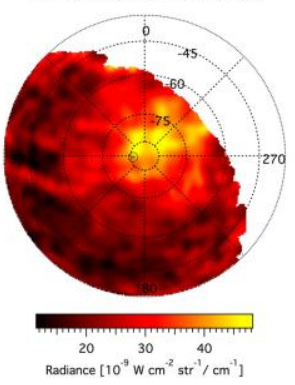

T91 (2013 May 23-34) : $663 \mathrm{~cm}^{-1}$ ( $\left.\mathrm{HC}_{3} \mathrm{~N}\right)$
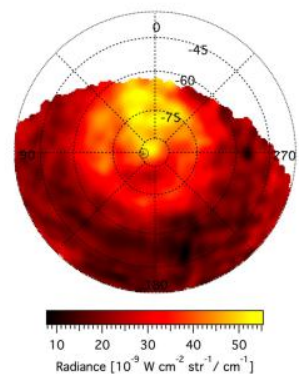

T101 (2014 May 16/18) : $663 \mathrm{~cm}^{-1}\left(\mathrm{HC}_{3} \mathrm{~N}\right)$

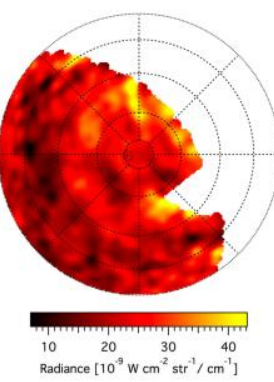

T106 (2014 Oct 23) : $663 \mathrm{~cm}^{-1}\left(\mathrm{HC}_{3} \mathrm{~N}\right)$

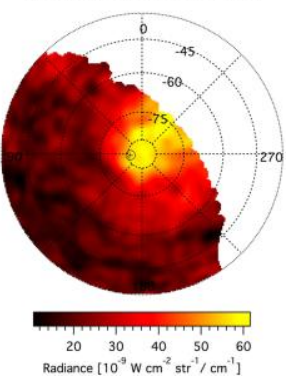



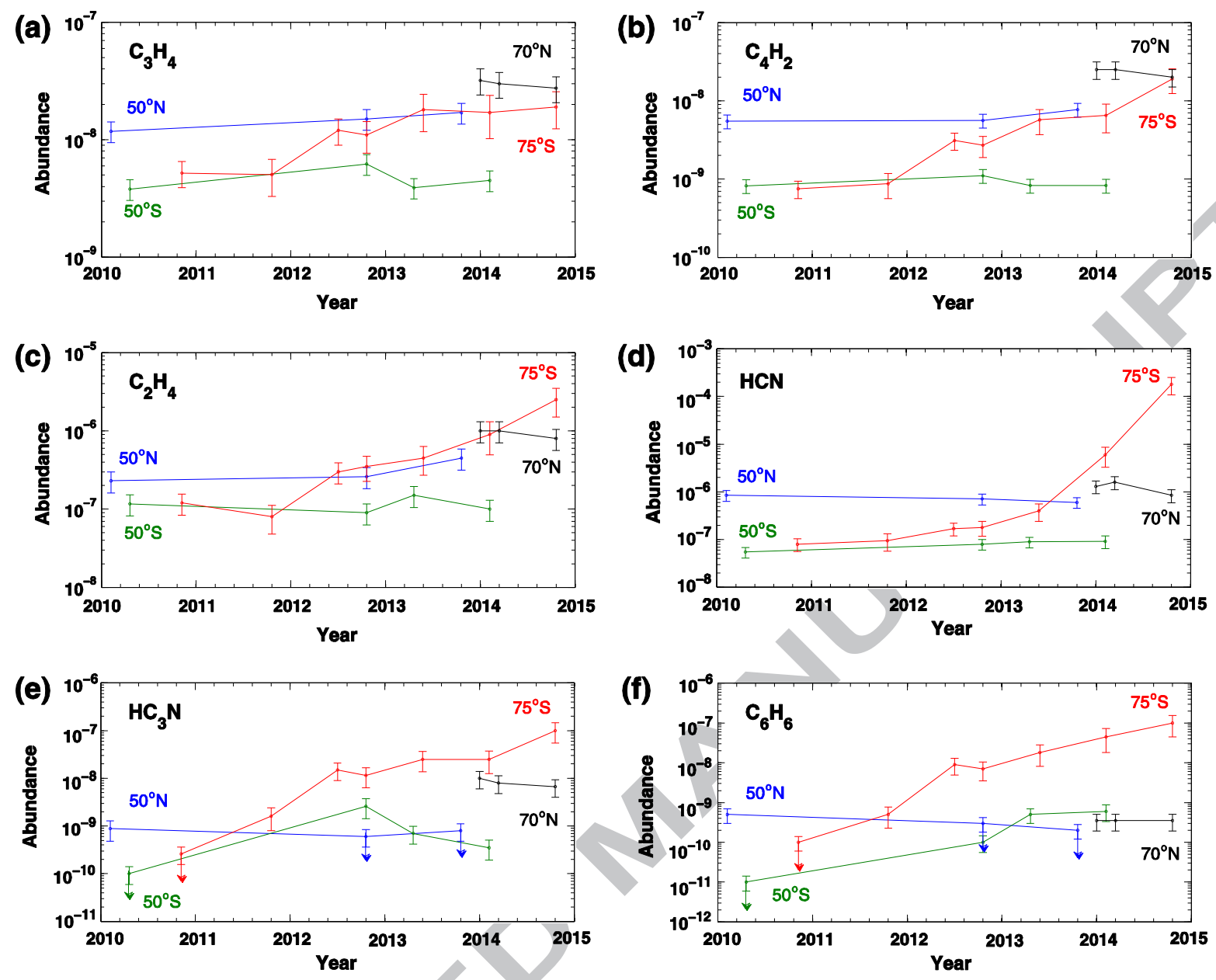
Highlights

- we infer the thermal and chemical evolution of Titan's stratosphere (2010-2014)

- we find different behavior for mid and high northern and southern latitudes

- the temperature decrease from 2010 to 2014 near the south pole reaches $40 \mathrm{~K}$

- the abundances of some species have increased dramatically since 2012 at $70^{\circ} \mathrm{S}$

- we bracket the time frame when the atmospheric flow reverses from $\mathrm{S}$ to $\mathrm{N}$ and $\mathrm{N}$ to $\mathrm{S}$ 